\title{
2021 North American Heatwave Fueled by Climate-Change-Driven Nonlinear Interactions
}

Samuel Bartusek ${ }^{*}, 1,2$, Kai Kornhuber ${ }^{2,3}$, Mingfang Ting ${ }^{2}$

(5

1. Department of Earth and Environmental Sciences, Columbia University, New York, NY, USA

2. Lamont-Doherty Earth Observatory, Columbia University, Palisades, NY, USA

3. Earth Institute, Columbia University, New York, NY, USA (1)

*Corresponding author: Samuel Bartusek, samuel.bartusek@columbia.edu

\section{$\underline{\text { Abstract }}$}

Extreme heat conditions in the North American Pacific Northwest in summer 2021 exceeded

14 prior heatwaves by a margin many would have considered impossible under current climate conditions. Associated severe impacts highlight the need to understand its physical drivers and relations to climate change, to improve projection and prediction of future extreme heat events.

17 Using observational data and a model experiment, we find that slow- and fast-moving components of the atmospheric circulation, along with soil moisture deficiency, interacted to trigger this 5-sigma event. Land-atmosphere feedbacks drove nonlinear amplification of its 0 temperature anomaly by $40 \%$, catalyzed by multidecadal temperature and soil moisture trends.

1 Over four decades of gradual warming, the event's temperature anomaly has become 10-100 22 times more likely, transforming from a $\sim 10,000$-year to a 100-1,000-year occurrence. Its 23 likelihood continues to increase, roughly exponentially, and it is projected to recur $\sim 20$-yearly by 242060 assuming unmitigated warming at a constant rate. 
$\underline{\text { Main }}$

26 Unprecedented heat conditions in the North American Pacific Northwest (PNW) in late June and

27 early July 2021 affected millions, likely led to deaths in the thousands, and promoted wildfires affecting air quality throughout the continent. CDC records suggest hundreds of excess deaths in both Washington and Oregon during the heatwave, while preliminarily almost 500 deaths in British Columbia have been officially attributed to heat, likely undercounting the true toll ${ }^{1,2,3}$. Heat-related emergency room visits spiked, totaling nearly 3,000 over 6 days (June 25-30) in the US PNW ${ }^{4}$. The event occurred in a region with high vulnerability to extreme heat, amplifying its dangers: air conditioning access in the Seattle and Portland metropolitan areas is among the lowest in the country ${ }^{5}$, while many PNW counties have among the largest outdoor agricultural worker populations and highest social vulnerability in the country ${ }^{6}$. Exacerbated by ongoing drought conditions (covering $95 \%$ of the US PNW by June $22^{7}$ ), wildfires sparked during and following the heatwave constitute some of 93 large active fires contributing to over 4 million acres burned across the western US as of August ${ }^{8}$. Western wildfire smoke has caused particulate matter pollution across the continent, for instance contributing to New York City's worst air quality in 15 years ${ }^{9}$.

Even as global warming causes an increase in the severity and frequency of heatwaves ${ }^{10,11}$, the magnitude of this event exceeded what many may have considered plausible under current climate conditions ${ }^{12}$. While heat records are typically broken by small increments ${ }^{13,14}$, during this event records were shattered by tens of degrees Celsius ${ }^{15}$. Such an unprecedented event raises the pressing question of whether heat extremes' future projections are too conservative or their mechanisms inadequately captured by climate models. It is therefore important to understand the event's physical drivers, and assess their connections with climate change. From an attribution perspective, was this anomaly so extreme to be considered virtually impossible regardless of climate change, or was it plausible and foreseeable, and even made more likely due to baseline warming? Further, were its drivers mechanistically altered by climate

52 future risk?

Whether any change in atmospheric dynamics or land-atmosphere interaction is

54 implicated in amplifying current and future heat extremes is a persistent question: common heatwave mechanisms may be modified by climate change beyond a shift in the background 
conditions. Mid-latitude summer heat extremes, typically triggered by anticyclonic circulation

57 anomalies, have often been associated with persistently amplified planetary-scale atmospheric

58 waves $^{16-20}$. Conditions favorable for wave amplification may become more frequent, likely due

59 to future weakening of the meridional temperature gradient ${ }^{21-23}$. Additionally, thermodynamic

60 land-atmosphere feedbacks can strongly amplify heatwave temperatures, often involving

61 nonlinear processes ${ }^{24-28}$. Land areas follow two distinct regimes of soil moisture-temperature

62 interaction: areas where soil moisture is too high or too low for its variability to affect

63 evapotranspiration, versus "transitional" climate areas, between wet and dry, where soil moisture

64 variability dominantly affects evapotranspiration and therefore temperature ${ }^{29}$. The central US is a

65 noted transitional-climate hotspot of strong soil moisture-temperature coupling ${ }^{29,30}$, but although

66 the presently-wet PNW is projected to dry due to warming ${ }^{31-33}$, and aridification of other wet

67 regions has been implicated in amplifying summer temperature variability (e.g. central

68 Europe $^{34}$ ), the PNW has not garnered similar focus on land-atmosphere contributions to its

69 temperature variability and their potential changes. 
a

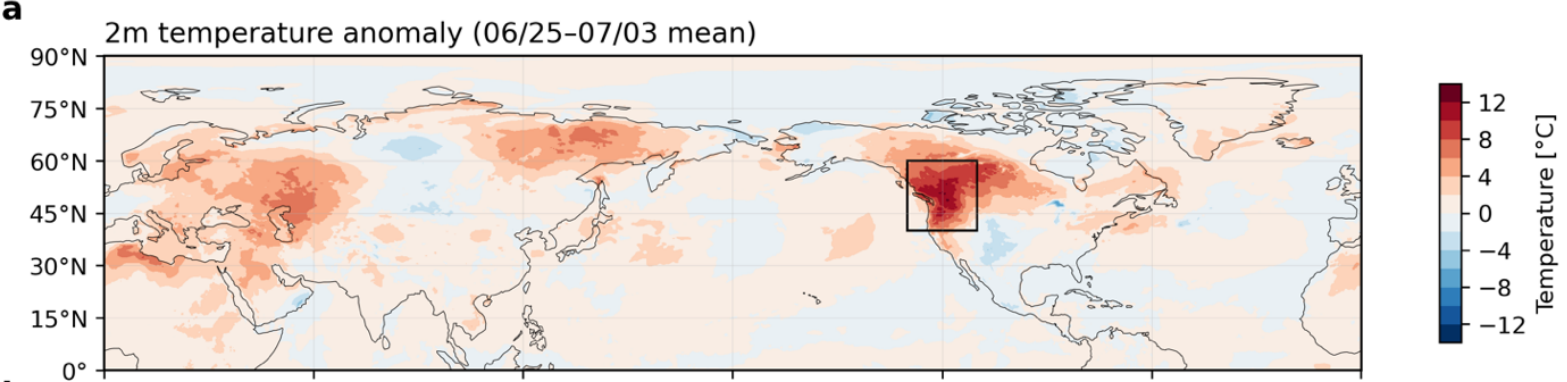

b

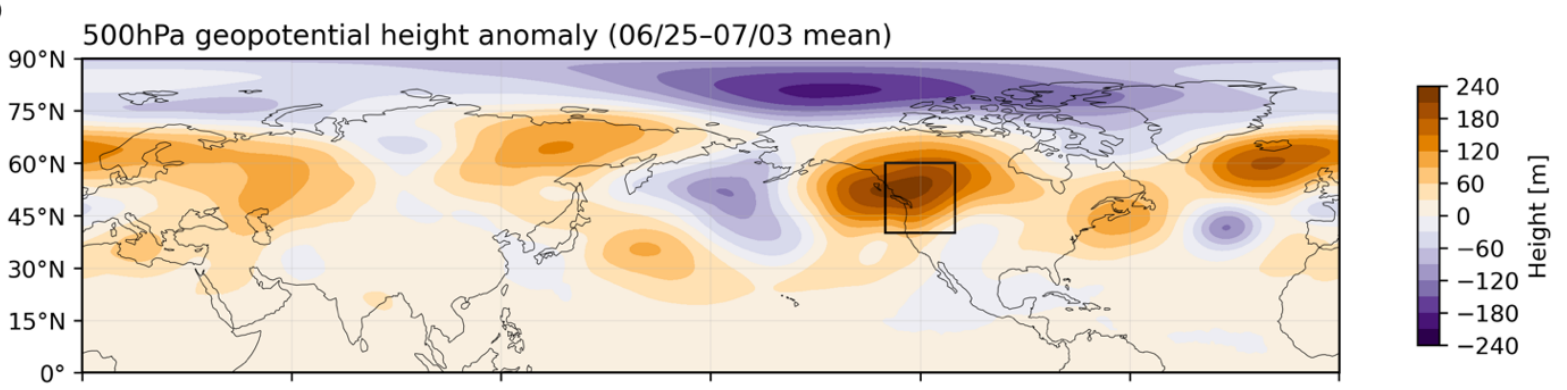

C

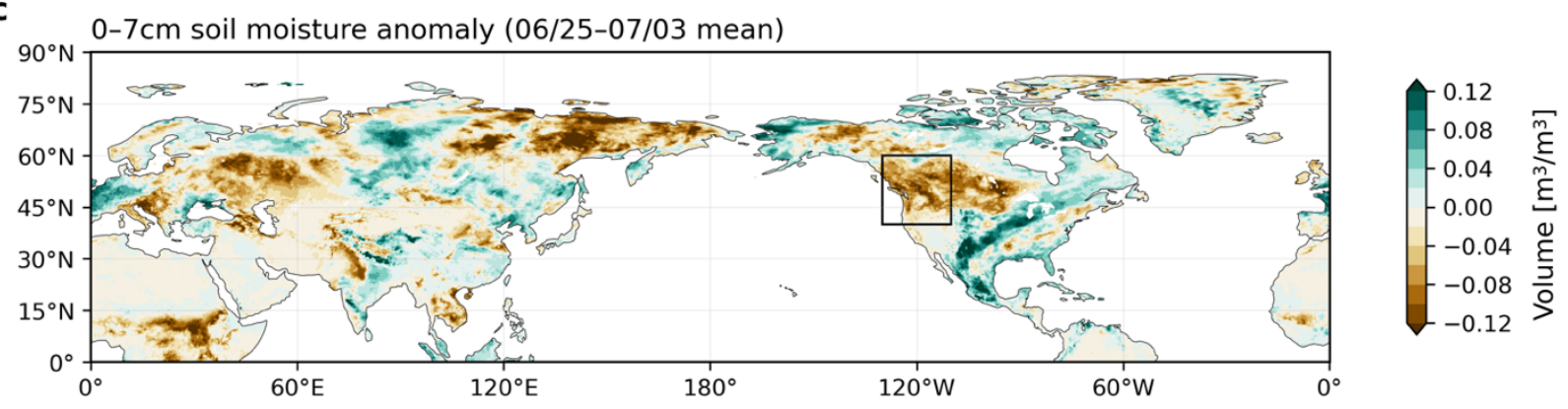

d Standardized anomalies throughout June 2021

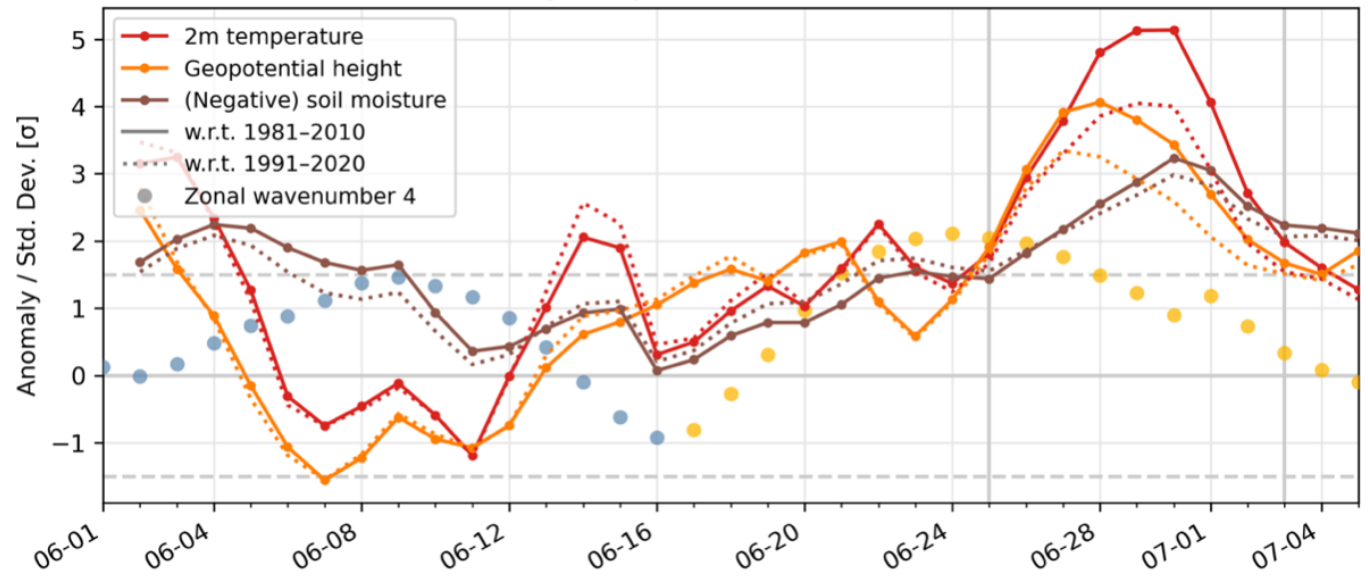

Fig. 1: Timing and location of the PNW heatwave and its associated atmospheric dynamical $h \mathrm{~Pa}$ ), and c) soil moisture anomalies in the Northern Hemisphere during the peak of the PNW heatwave (June 25th-July 3rd, 2021), and d) their temporal evolution since the beginning of June averaged over the PNW (black box in a-c); $40-60^{\circ} \mathrm{N}, 110-130^{\circ} \mathrm{W}$; temperature over land only). During the heatwave, much of Northwestern North America experienced extreme 
deviations, respectively, with respect to their 1981-2010 climatologies (3-day running-mean). Standardized anomalies with respect to the 1991-2020 climatological period are compared as dotted lines. Also shown in $\boldsymbol{d})$ is the amplitude of a zonal wavenumber-4 disturbance in the midlatitude upper-atmospheric circulation, derived from 300hPa meridional wind anomalies over $37.5^{\circ}-57.5^{\circ} \mathrm{N}$ (15-day running-mean, standardized with respect to a 1981-2010 monthly climatology), colored blue when in negative phase and yellow in positive phase (see Methods). This wave corresponds to 4 regions of positive (alternating with 4 of negative) geopotential height anomalies encircling the hemisphere, visible in $\boldsymbol{a}-\boldsymbol{c})$ with associated temperature and soil moisture anomalies affecting the PNW, central Eurasia, and Northeastern Siberia.

\section{Unprecedented PNW heat conditions and contributing factors}

Anomalous surface temperatures during the PNW heatwave were accompanied by extremely high geopotential height and exceptionally low soil moisture, respectively exceeding their climatological 5-, 4-, and 3-standard-deviation regional-average levels (Fig. 1). During the peak of the event, the 9-day average (June 25-July 3) temperature exceeded $12^{\circ} \mathrm{C}$ above normal in parts of the PNW. Such heat conditions were historic, yet their remarkability has declined: PNWaverage (land) temperature surpassed 5 standard deviations relative to the 1981-2010 climate but only 4 standard deviations relative to 1991-2020, with shifts in the same direction for geopotential height and soil moisture (Fig. 1d). Assuming normality of each date's historical temperature distribution (which is not statistically contradicted; Supplementary Fig. 1), a change from 5 to 4 standard deviations implies a $\sim 100$-fold increase in event probability.

While the severity of the PNW's heat during this period was hemispherically unique, it was also embedded in a broader phenomenon - a hemisphere-wide pattern of concurrent anomalies extending from the land surface to the mid-atmosphere (Fig. 1a-c). Central Eurasia and northeastern Siberia both experienced warm anomalies, dry soils and high geopotential heights, and the North Atlantic constituted a fourth region of high geopotential height. Together with intervening regions of cool, wet, and low anomalies, this pattern comprised a circumglobal wavenumber- 4 disturbance (with 4 peaks and 4 troughs in each variable encircling the northern midlatitudes), a pattern which has been associated with North American wildfires ${ }^{35}$. An anomalous wavenumber-4 component of the upper-atmospheric circulation (see Methods) was established since June 19 (before the main heatwave period), and strongly amplified ( $>1.5 \sigma)$ since June 21 (Figure 1d). The same wave was amplified in the opposite phase in early June, cooling the PNW. 
However, the PNW experienced markedly stronger temperature and height anomalies

111 than other positive nodes of the hemispheric wave, despite similar soil moisture anomalies

112 (compare Fig. 1b and 1c). At the same time, regional temperature continued rising during the 113 event after geopotential height had peaked, mirroring the direction of soil moisture anomalies.

114 These observations suggest a potential role for both shorter-term atmospheric dynamics and 115 land-atmosphere feedbacks amplifying and prolonging the PNW heatwave. 


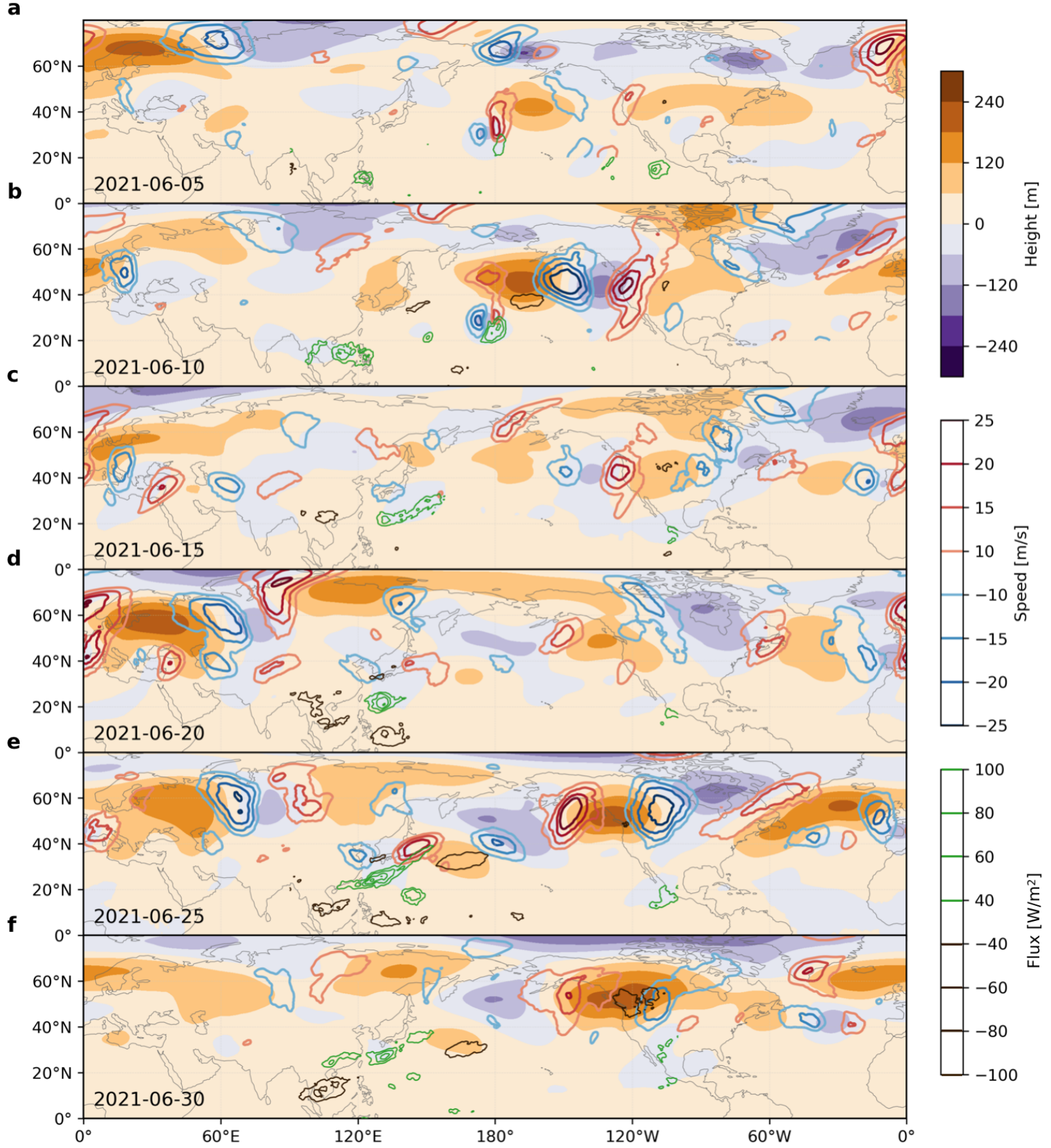

Fig. 2: Atmospheric dynamics during June 2021 leading to the anomalous geopotential heights associated with the PNW heatwave. a-f): Geopotential height (filled contours), meridional wind speed (red and blue contours), and outgoing longwave radiation (OLR; green and dark brown contours) anomalies averaged over 9-day periods centered on the annotated dates. For clarity, the meridional wind field is shown above $20^{\circ} \mathrm{N}$ and the OLR field is shown within $90^{\circ} \mathrm{E}-100^{\circ} \mathrm{W}$ (roughly the Pacific Ocean). a) shows the 9-day mean surrounding 06/05, when geopotential heights were high in the PNW accompanying a heatwave, with low and high geopotential height regions extending westward over the Pacific and forming a tripole. By 06/10 
over the PNW, and begun to constitute part of a wavenumber-4 pattern in meridional wind and geopotential height encircling the midlatitudes. Over 06/10-06/20 (c-e)) this wave shifted phase longitudinally, eventually placing high geopotential height over the PNW. Throughout late June $(\boldsymbol{d}$-f) the wavenumber-4 pattern persisted and amplified, causing extreme temperatures and dry soils in central Europe, Siberia, and the PNW, and was reinforced by a Rossby wavetrain emanating from the subtropical western Pacific.

\section{Anomalous geopotential heights fueled by the interaction of two distinct Rossby waves}

Mutually-reinforcing slow- and fast-moving circulation features provided atmospheric dynamical forcing for the heatwave, each carrying potential climate linkages that may result in increased risk of concurrency and associated extreme impacts. First, the planetary wavenumber-4 circulation anomaly persisted during much of June, producing synchronized climate extremes throughout the hemisphere, and dramatically amplified in late June boosting temperatures and drying soils in the PNW (Fig. 2; see caption). Accordingly, in late June the jet assumed a persistent anomalous "wavy" configuration with strong meridional wind meanders (Fig. 2, Supplementary Fig. 3). Its northern excursions, encircling anticyclonic anomalies, formed an anomalous polar jet that together with the subtropical jet created a midlatitude waveguide, and zonal-mean temperature anomalies then peaked where zonal wind gradients were strongest ( $\sim 60^{\circ} \mathrm{N}$; Supplementary Fig. 3). These conditions represent a fingerprint for planetary wave amplification projected to become more frequent with warming, likely connected to a weakening meridional temperature gradient ${ }^{21,22}$. Secondly, convection in the western subtropical Pacific (south of Japan) generated negative outgoing longwave radiation (OLR) anomalies, exciting a late-June Rossby wavetrain extending towards North America. This synoptic wavetrain locked phase with the existing hemispheric wave, amplifying the PNW's geopotential height and temperature anomalies and perhaps also strengthening the hemispheric wave (Fig. 2). Recent findings show that typhoons undergoing extratropical transition south of Japan can heighten PNW wildfire risk by inducing downslope easterly winds across the Cascade Range that adiabatically warm and dry ${ }^{36,37}$, as demonstrated during 2021. A projected northward shift in typhoon tracks in this region under global warming ${ }^{38-40}$ could increase the risk of such events. 
a
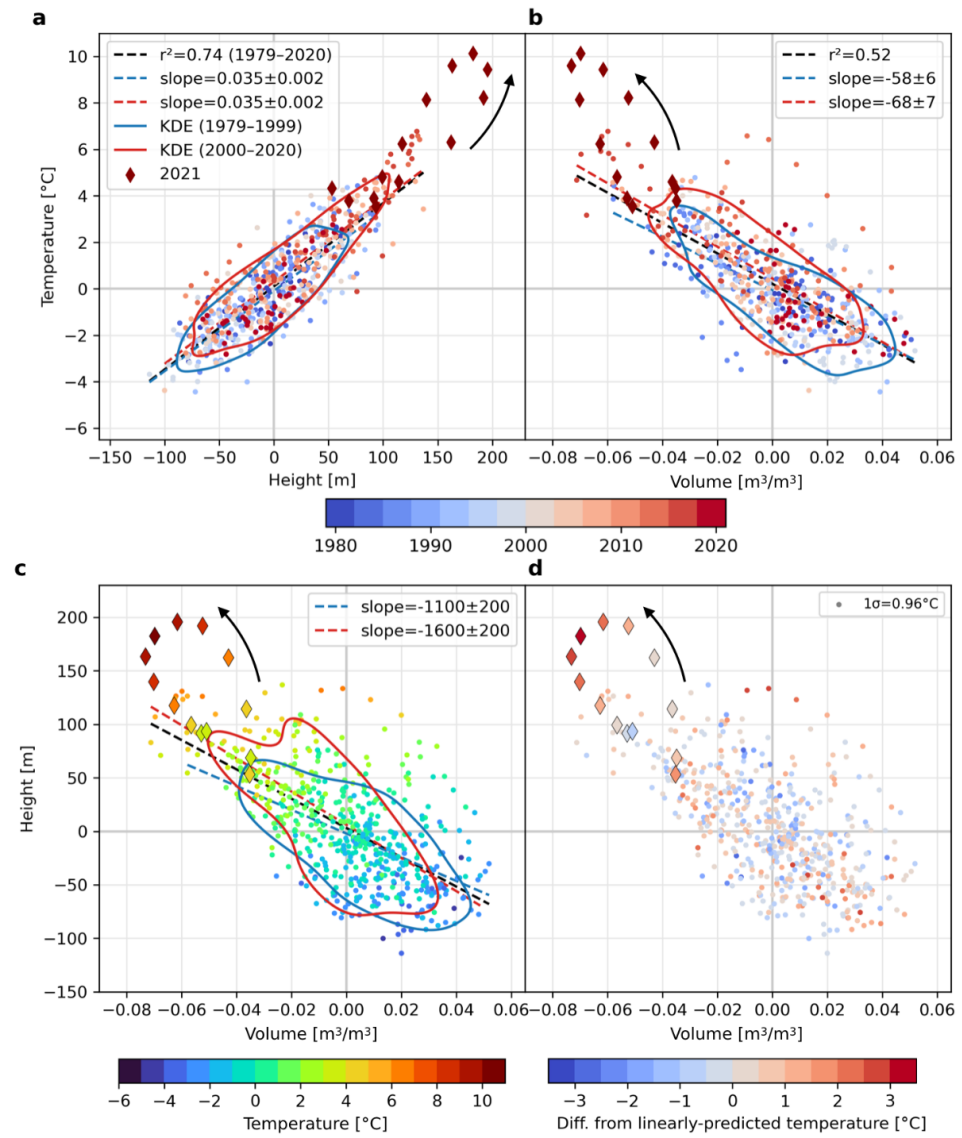

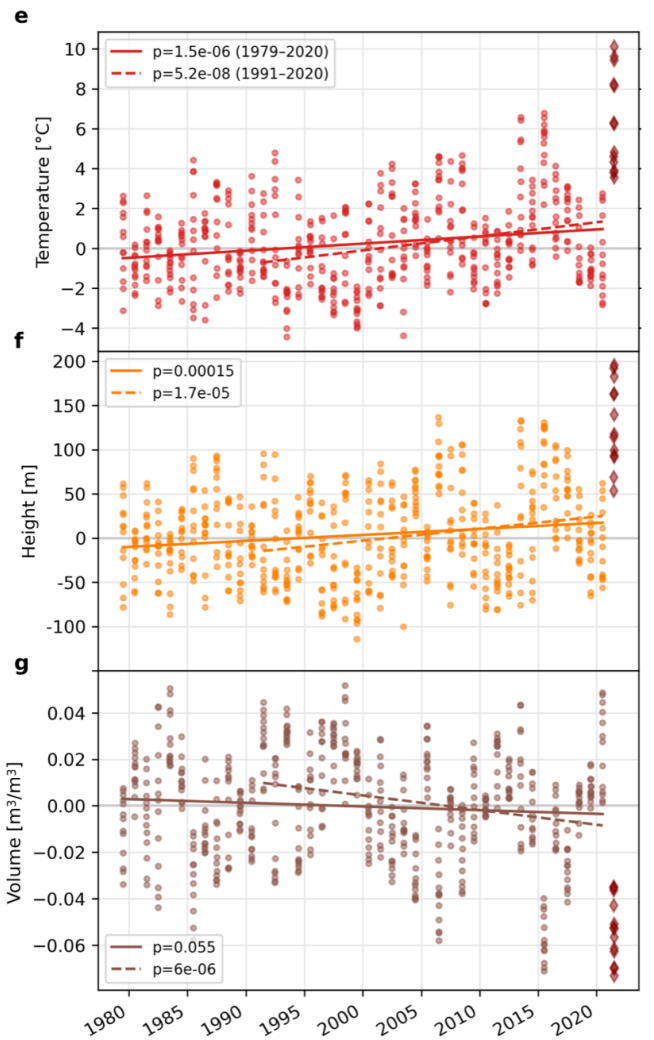

156

Fig. 3: Nonlinear interactions of common drivers and their long-term trends. a) shows 3-day running means of PNW-mean $2 m$ (land) temperature versus geopotential height, centered on each day from June 23-July 5, spanning 1979-2021. 1979-2020 markers are colored according to their 3-year window. Dark red diamonds show 2021 values, clearly departing but not entirely separate from the underlying distribution; the arrow indicates their evolution through time. The black dashed line shows the historical (1979-2020) linear correlation between geopotential height and temperature, with $r^{2}$ noted in the legend. Red and blue dashed lines show the 19791999 and 2000-2020 correlations, respectively, with slopes noted in the legend (with 90\% confidence intervals). Red and blue curves illustrate the 0.5 contour of a Gaussian Kernel Density Estimation (KDE) of the variables' 2-dimensional distribution for each of the two periods (i.e., the contour above/below which 50\% of the estimated density lies), showing a shift between the periods towards the 2021 observed values. b): same as a) for soil moisture versus temperature anomalies. c): same as a) and b) for soil moisture versus geopotential height anomalies, with markers colored according to temperature anomaly. d) shows the same points as c) but colored according to the difference between the observed temperature (colors in c)) and the temperature predicted at each soil moisture and geopotential height value by a multiple linear regression using both as inputs (see Supplementary Fig. 4), indicating that the event's highest temperatures involved nonlinear contributions of $\sim 3^{\circ} \mathrm{C}$ (out of a total $10^{\circ} \mathrm{C}$ anomaly). $e$ g) show the same data in $\boldsymbol{a}-\boldsymbol{d})$ plotted against year, shown individually for temperature (e)), geopotential height (f)), and soil moisture (g)), with linear trends over 1979-2020 and 19912020 (p-values in legends). 


\section{Heat contributions from nonlinear land-atmosphere interactions favored by long-term}

\section{$\underline{\text { trends }}$}

180 Interactions in the land-atmosphere system intensified the heatwave, likely providing $\sim 3^{\circ} \mathrm{C}$ in nonlinear contributions (of the $\sim 10^{\circ} \mathrm{C}$ peak regional-mean heat anomaly) above the heat accounted for by linear processes (Fig. 3). The heatwave's proximate cause was extreme anomalies in common heatwave drivers - high geopotential height, resulting from wave-wave interaction, and dry soil, which both exceeded their historical (1979-2020) distributions yet largely followed expected relationships between them (Fig. 3a-c), as in simulated recordshattering heatwaves in similar regions ${ }^{15}$. However, the heatwave's peak temperatures markedly exceeded linear regressions relating temperature to geopotential height or soil moisture (by 4$5^{\circ} \mathrm{C}$ ), which are otherwise strongly predictive (Fig. 3a-b). A multiple regression, incorporating their simultaneous anomalies, confirms strong nonlinear temperature amplification, maximizing during the event's peak at $\sim 3^{\circ} \mathrm{C}$ (i.e., a $40 \%$ amplification of $\sim 7^{\circ} \mathrm{C}$ ), representing a 3 -standarddeviation amplification (Fig. 3c-d). Soil interaction likely drove these nonlinearities, since amplification increased as soils continued to dry despite geopotential height stagnating and declining (Fig. 3d, Fig. 1d, consistent with Miralles et al. ${ }^{26}$ ). From a spatial perspective, soil dryness across much of the region from a beginning-June heatwave persisted throughout June, even during cool periods, establishing preconditions for land-atmosphere feedbacks to amplify this heatwave (Supplementary Fig. 5; Fig. 1d). Accordingly, low evaporative fraction anomalies collocated with many of the event's highest temperature anomalies (primarily low- to midelevation interior areas with semi-arid and Mediterranean climates; Supplementary Fig. 6), confirming feedbacks' importance - meanwhile, many such areas are experiencing multidecadal summer drying, warming, and temperature variability increases (Supplementary Figs. 6, 7; see Conclusions). Additionally, since upwind drought can enhance heatwaves via advection ${ }^{41}$, dry anomalies east of the PNW (Figure 1c) may have also provided amplification via strong easterlies.

Furthermore, historical PNW trends have favored the nonlinear behavior amplifying the 205 heatwave - thus while 2021's extreme heat was unprecedented, it was nevertheless 206 mechanistically linked to regional climate change. First, the distributions of driving variables 207 have individually shifted towards 2021's observed conditions: late-June-early-July temperature, 
208 geopotential height, and soil dryness have increased over 1979-2020, with trends accelerating 209 over 1991-2020 (Fig. 3e-g). Consequently, these variables' historical extremes most closely 210 approaching 2021 conditions tend to occupy more recent years (> 2010; Fig. 3a-b). Second,

211 estimated bivariate distributions combining these variables have shifted towards high

212 temperature and geopotential height and dry soils occurring simultaneously (Fig. 3a-b). Notably,

213 extreme temperatures approaching 2021 conditions tended also to be displaced above the linear

214 driver regressions (Fig. 3a-b). Indeed, while bivariate distributions (contours) have generally

215 shifted following their underlying regressions, the slopes describing the temperature and 216 geopotential height relationships with soil moisture have strengthened, indicating magnified

217 temperature and geopotential height anomalies relative to soil moisture anomalies (Fig. 3b-c).

218 Temperature-height bivariate density contours also potentially suggest a changing relationship 219 particularly in the distribution's positive extremes, despite the unchanging linear relation (Fig. 220 3a), suggesting a change specific to heatwave mechanisms. While these conclusions hold when 221 considering all of June and July (Supplementary Fig. 8), we note that the late-June-early-July 222 period has exhibited especially pronounced trends in temperature, geopotential height, soil 223 moisture, and their interannual and intra-annual variabilities (Supplementary Figs. 2, 9), perhaps 224 indicative of advancing summer onset ${ }^{42}$. 
a

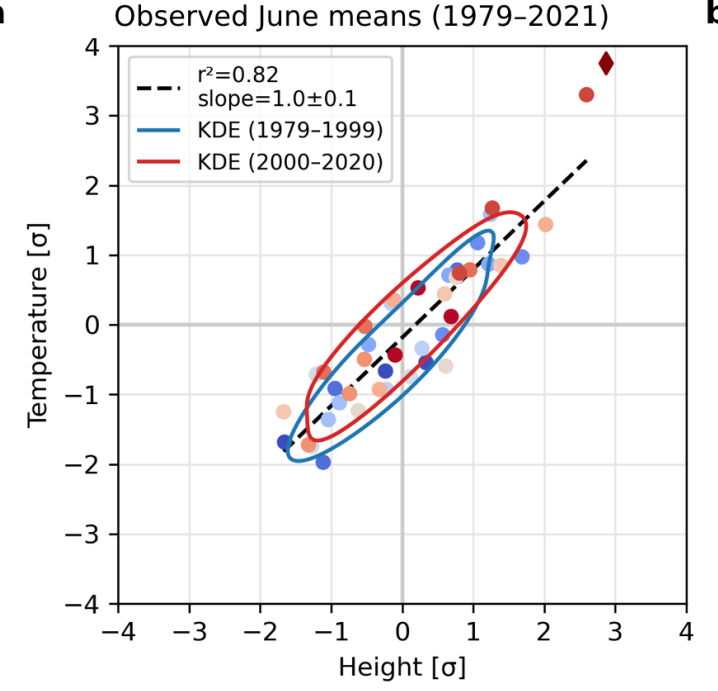

C

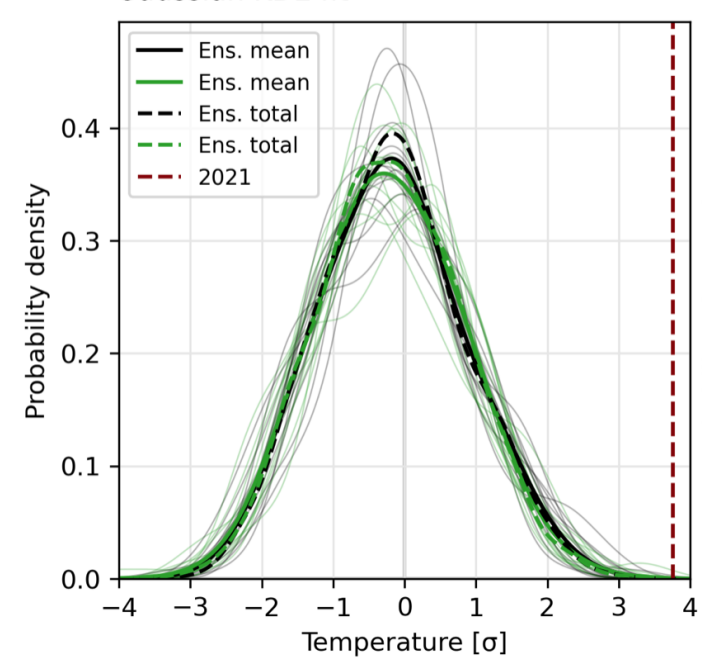

b

Model June means (1870-2010)

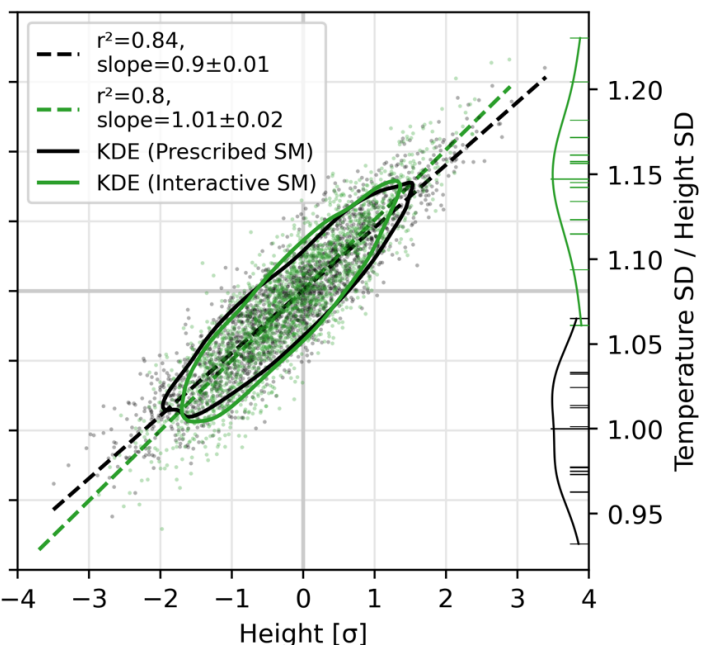

d

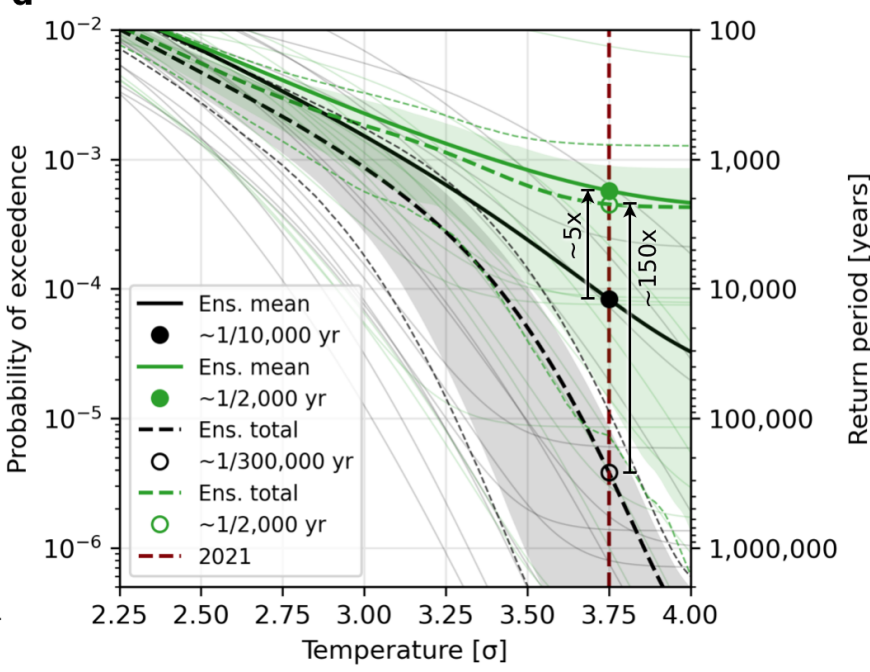

Fig. 4: Modeled PNW temperature variability and event return period, with versus without soil moisture interaction. June-mean PNW-mean surface temperature anomalies versus geopotential height anomalies, from a) reanalysis (1979-2021) and b) the CAM5-GOGA model experiment (1870-2010; see Methods), with all member-months from the Prescribed soil moisture ensemble in black and the Interactive ensemble in green. Reanalysis anomalies are standardized with respect to the 1981-2010 climatology, and model anomalies with respect to all Prescribed member-months (1870-2010). Linear correlations, $r^{2}$ values, slopes, KDE contours (with 1.25x smoothing in a) and showing the 0.3 instead of 0.5 contour in b)), and marker year coloring (a)) are shown as in Fig. 3. The right y-axis of b) compares the ratio of each member's geopotential height standard deviation (Prescribed members in black; Interactive members in green) to the temperature standard deviation over all Prescribed member-months. Longer lines show ensemble-total ratios; curves show KDEs extending to ensemble maximum and minimum ratios. The Prescribed ensemble-total ratio is identically 1 (but ratio varies between members) versus $\sim 1.15$ for the Interactive ensemble-total, indicating a $\sim 15 \%$ greater ratio of temperature variability versus geopotential height variability when soil moisture is interactive. c) shows KDEs fit to each ensemble member, and ensemble-mean (solid curve) and ensemble-total (dashed curve) distributions. The vertical dashed line marks the 2021 observed June-mean 
standardized temperature anomaly $(\sim 3.75 \sigma)$. d) shows exceedance probability $(1-C D F)$ for each distribution in $\mathrm{c}$ ), with bootstrapped $90 \%$ (dashed lines) and $80 \%$ (shading) confidence intervals for ensemble-total curves (see Methods). The right y-axis shows return period (exceedance probability's inverse); the legend notes estimated return periods for the 2021 anomaly for Prescribed and Interactive ensemble means and totals. Vertical arrows illustrate the likelihood enhancement of the 2021 monthly-scale heat anomaly attributable to soil moisture interactivity: $\sim 5$-fold between ensemble means and 150-fold between ensemble totals.

\section{Role of soil moisture in amplifying PNW temperature extremes}

Using a tailored model experiment we determine that soil moisture feedbacks likely induced a many-fold increase in the probability of the PNW heatwave on a monthly timescale. A climate model, forced by historical sea surface temperatures, is run with versus without soil moisture interactivity (hereafter, Interactive and Prescribed ensembles), and we compare June-mean surface (not $2 \mathrm{~m}$ ) temperature model output with observations. We first confirm that the observed June-mean 2021 surface temperature was extreme (Fig. 4a), with temperature exceeding its height regression (see Methods). We find that soil moisture interaction increases the ratio of temperature variability versus geopotential height variability, robustly across all Interactive members, altogether by $\sim 15 \%$ (Fig. $4 \mathrm{~b}$, right axis). Consistent with previous research ${ }^{43}$, temperature variability increases modestly in Interactive members, accompanying strongly increased mean temperature (Supplementary Fig. 10). Accordingly, the height-temperature regression slope across all member-months is significantly higher in the Interactive configuration, adjusting from $\sim 90 \%$ of, to roughly equivalent to, the observed slope (Fig. 4b). However, this linear slope increase may underestimate the change toward the distributions' tails, i.e. during extremes (Fig. 4b, KDE contours).

The likelihood of June 2021's temperature anomaly $(\sim 3.75 \sigma)$ therefore significantly increases when soil moisture interacts with the atmosphere (while it remains low, likely given the model period of 1870-2010), estimated via ensemble means of KDEs fit to each member and an ensemble-total (i.e., all member-months) KDE. The ensemble-mean distributions estimate a $\sim 5$-fold increase in the likelihood of the observed anomaly between Prescribed and Interactive ensembles, transforming from an extremely unlikely $\sim 10,000$-year event to a $\sim 2,000$-year event. However, the ensemble-total distributions (which incorporate all member-months simultaneously, expanding the sample size for each return period calculation from $n=14$ 
Non-peer reviewed preprint submitted to EarthArXiv (in review at Nature Climate Change)

275 members to $n=1,974$ member-months) estimate an even greater likelihood increase of $\sim 150$-fold, 276 as the event is nearly impossible without soil moisture interaction $(\sim 300,000$-year $)$. 
Non-peer reviewed preprint submitted to EarthArXiv (in review at Nature Climate Change)
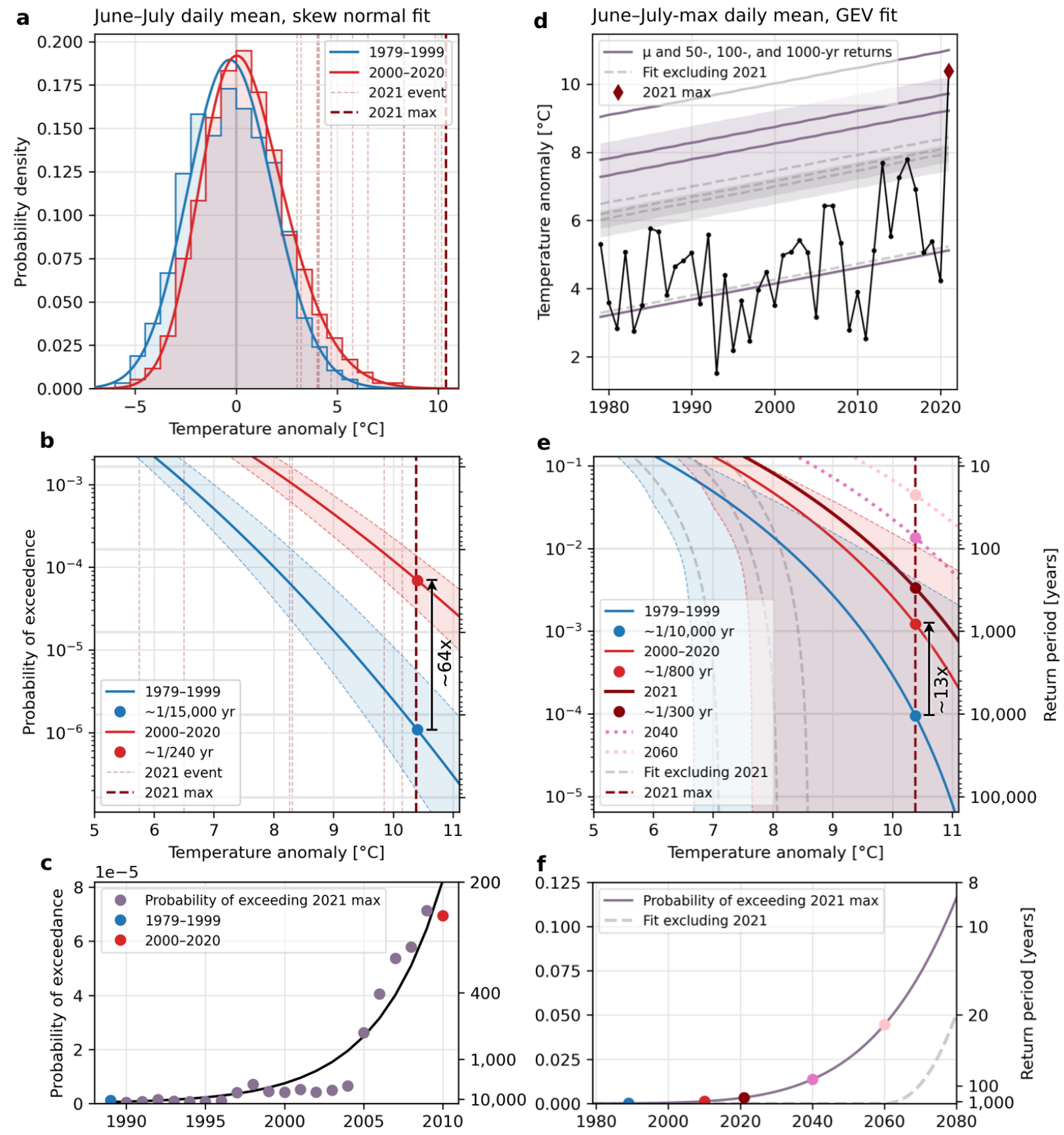

Fig. 5: Event return period estimates over recent decades. Estimates of the 2021 heatwave's likelihood over recent historical periods, via two complementary methods: $(\boldsymbol{a}-\boldsymbol{c}))$ a skew normal distribution fit to June-July daily mean PNW-mean temperatures and (d-f)) a nonstationary Generalized Extreme Value (GEV) distribution fit to yearly June-July-maximum daily mean temperature. a) shows histograms of June-July daily temperatures over 1979-1999 and 20002020 (each $n=1,281$ ), their fitted skew normal distributions (displaying positive and increasing skewness; Supplementary Figs. 1, 7, 9), and temperatures over June 23-July 52021 (dashed vertical lines). b) shows associated exceedance probabilities, return periods, bootstrapped $90 \%$ confidence intervals, and estimated 2021 heatwave $\left(\sim 10.4^{\circ} \mathrm{C}\right)$ return periods, demonstrating a $\sim 64-f o l d$ likelihood increase over the 21-year period shift. Yearly return period (right y-axis, 
shared with $\boldsymbol{e}$ )) is the inverse of daily exceedance probability (left y-axis) divided by 61 to capture the probability of one day each year exceeding a given threshold. c) provides estimated 2021 event probabilities (daily, left y-axis) and return periods (yearly, right y-axis) for shifting 21-year periods between the two in b), with a fitted exponential curve. d) shows GEV fits overlaid on yearly June-July-maximum daily temperature, both including (purple) and excluding (gray dashed) the 2021 event, plotting the linearly-evolving location parameter $\mu$, and 50-, 100-, and 1000-year return levels, with 50-year return bootstrapped 90\% confidence intervals. The 2021 heatwave lies between the 100-and 1000-year return levels of the including-2021 fit evaluated at 2021, but outside its 1000-year return level evaluated at 1979 (and lies outside the 1000-year return level for the excluding-2021 fit evaluated at any year). e) plots return periods for the historical periods in b) (i.e., fits evaluated at each period's central year) and 2021, and also for 2040 and 2060 for the including-2021 fit. The including-2021 fit, despite its methodological contrasts with $\boldsymbol{a}-\boldsymbol{c})$, nevertheless in rough agreement estimates the 2021 heatwave as a 10,000-year event in the 1979-1999 climate and demonstrates likelihood increases of multiple orders of magnitude reaching a return period of hundreds of years in the 2000-2020 climate - and greater likelihood in 2021. In f), GEV fits (under constant linear warming) provide likelihood estimates for a future event exceeding 2021 as in c) (dots mark the periods and years in e)), projecting future probabilities far exceeding those estimated until today, increasing roughly exponentially.

\section{Increasing event likelihood driven by climate change}

Recent climate change has rapidly increased the likelihood of the 2021 heatwave: over a 21-year shift surrounding the year 2000, such an event multiplied in probability from a roughly 10,000year event to a multi-hundred-year event, with even higher current and future likelihood (Fig. 5). These findings synthesize two complementary methods: $i$ ) fitting a skew normal distribution to daily mean PNW-mean temperature anomalies throughout all of June-July, analyzing two multidecadal historical periods (Fig. 5a-c), and ii) fitting a nonstationary Generalized Extreme Value (GEV) distribution to just each year's June-July maximum anomaly (Fig. 5d-f). The GEV analysis provides a complementary perspective through its targeted application to extreme values and its ability to project future event probabilities, and is an established approach to estimate return periods for climate extremes ${ }^{44,45}$, while the whole-June-July analysis retains full sample sizes $(n=1,281)$ for fitting historical distributions and characterizing past changes in heat events in more detail than single yearly maxima ( $n=42$ or 43 ), and allows investigation of historical changes through separate sub-period fits. Since the 2021 event far exceeded the historically observed range (Fig 5a, 5d), caution is warranted when interpreting fitted distributionscomparison against empirical return periods (Supplementary Fig. 11) indicates, however, that historical probability ratios may be underestimated. Finally, it is important to note that assessing 
the probability of this event's temperature magnitude alone - despite its clear multivariate extreme characteristics-likely conservatively estimates ongoing event likelihood increases given other variables' simultaneous trends.

First, comparing whole June-July distributions, the probability of 2021's observed temperature anomaly increased 64-fold during the 21-year shift (1979-1999 versus 20002020 ), as warming transformed the heatwave from a $\sim 15,000$-year event to a $\sim 230$-year event (Fig. 5b). Over the decades, the event likelihood increased nearly continuously, roughly following an exponential curve (Fig. 5c). These changes are potentially connected not only to shifting mean temperatures but also changing variability: temperatures within each period, which deviate significantly from normal, display positive skewness that increased between periods (Fig. 5a, Supplementary Figs. 1, 7, 9, 11). While pointwise (station-based) daily maximum and minimum temperatures in July-August show small skewness in the PNW and have not displayed strong historical increases ${ }^{46}$, here we analyze regional-mean temperature and consider an earlier summer period. We find that in July, pointwise skewness and its trends generally follow patterns found for daily maximum and minimum July-August temperatures ${ }^{46}$, but that they are more positive in June than July (Supplementary Fig. 7), and we note that research has projected future modeled temperature skewness increases under $\mathrm{CO}_{2}$ forcing in the PNW, likely linked to soil moisture interaction ${ }^{47}$.

The GEV analysis, despite its substantial methodological differences, reaches similar conclusions: the observed heatwave became $\sim 13$ times more likely and its rarity fell from a $\sim 10,000$-year to an $\sim 800$-year event over the 21 years, and by 2021 has become a $\sim 300$-year event (Fig. 5e). Furthermore, if warming continues linearly, the probability of an event exceeding 2021 will increase roughly exponentially, projected to recur $\sim 20$-yearly by 2060 and $\sim 10$-yearly before 2080 (Fig. 5e-f). We apply a GEV fit including 2021 in addition to excluding it, following Van Oldenborgh et al. ${ }^{45}$ and Philip et al. ${ }^{12}$ in assuming it is drawn from the same distribution as historical observations since the study region was not selected solely to maximize local extremity but rather for a large-scale regional perspective, reducing selection bias. The excluding-2021 fit estimates a finite maximum possible temperature well below the 2021 observation even under current warming (Fig. 5d), questioning its validity, and, not including all observations to date, is not suitable for future projection. Ultimately, both fits underscore the dramatic increases in heat extreme probabilities forced by even gradual warming: the including- 
Non-peer reviewed preprint submitted to EarthArXiv (in review at Nature Climate Change)

3562021 fit estimates that a 1000-year event in 1979 would currently represent a 50-year event, 357 while such an event according to the excluding-2021 fit has been surpassed multiple times 358 already (Fig. 5d). 


\section{Conclusions}

361

362

363

364

365

366

367

368

369

370

371

372

373

374

375

376

377

378

379

380

381

382

383

384

385

386

387

388

389

390

Given the 2021 heatwave's extreme magnitude, an important question is whether it represents a black swan event, effectively unforeseeable no matter the climate conditions; a grey swan event $^{48}$, plausible by linking to common drivers and even made more likely by background warming; or further, an event whose drivers do not act stationarily with respect to a moving background climate but are instead mechanistically altered by climate trends - with event likelihood increasing beyond that induced by a background shift. We find that, although this event was unprecedented by large margins, it was traceable to common drivers, which exhibited extreme anomalies ${ }^{15}$. Interacting circulation features provided highly anomalous atmospheric dynamical forcing (4-sigma geopotential height exceedance), and land-atmosphere feedbacks amplified the event's severity by $\sim 40 \%$. However, we furthermore find that the nonlinear interactions amplifying this heatwave were mechanistically linked to trends in temperature, soil moisture, and geopotential height relationships enhancing their likelihood, possibly suggesting a long-term shift in feedback behavior underway in the region compounding background warming. Warming-forced midlatitude land drying ${ }^{31,32}$ could shift wet regions, such as the PNW, towards a transitional climate between wet and dry, possibly strengthening land-atmosphere feedbacks and temperature variability ${ }^{29}$. However, the PNW has received little examination of shifting soil moisture-temperature coupling, despite that some PNW areas already occupy transitional regimes during summer ${ }^{49,50}$ and dry soil-hot day linkages in the region are recognized ${ }^{51}$. Our findings indicate that rapid soil drying (particularly in early summer, regionally drying 7\% between 1979-1999 and 2000-2020; Supplementary Fig. 2) is likely already altering extreme heat mechanisms: in many of the 2021 heatwave's anomalously hottest areas, long-term decreasing evaporative fraction trends (Supplementary Fig. 6) are collocated with increasing temperature variability trends (Supplementary Fig. 7). Notably, temperature variability increases are strongest where soil moisture is climatologically moderate instead of the driest areas (Supplementary Fig. 7) - thus in the PNW, drying may increase temperature variability more than in already-arid regions like the southwestern $\mathrm{US}^{29}$. In accordance with recent research demonstrating the emergence of heat-amplifying land-atmosphere feedbacks in regions not historically experiencing them ${ }^{28}$ and, moreover, model projections of mid-21stcentury soil moisture regime shifts over widespread land areas including the $\mathrm{PNW}^{33}$, we suggest that the 2021 heatwave may represent an alarming manifestation of a shifting regime across 
391 much of the PNW from wet to transitional climate, making such events more likely through 392 strengthened soil moisture-temperature coupling - however, further research is required to 393 substantiate this.

$394 \quad$ Our results underscore that even gradual warming over a short, recent period of four 395 decades dramatically transformed the character of this event. Over 21 years surrounding the year 3962000 , it became 10-100 times more likely (synthesizing independent methods), and was 397 refigured from nearly impossible ( 10,000-year return period) to plausible and somewhat 398 expected (hundreds of years return period). Continued warming at a constant rate will cause the 399 probability of an equal or stronger event to not only increase but accelerate, rising roughly 400 exponentially — becoming a $\sim 20$-year occurrence around 2060 and a $\sim 10$-year occurrence before 4012080 - until heating is slowed. 
Non-peer reviewed preprint submitted to EarthArXiv (in review at Nature Climate Change)

403

404

405

406

407

408

409

410

411

412

413

414

415

416

417

418

419

420

421

422

423

424

425

426

427

428

429

430

431

432

433

\section{Methods}

\section{Reanalysis data}

All reanalysis data are provided by ECMWF's ERA $5^{52}$, obtained at $\sim 0.25^{\circ}$ and 6 -hourly resolution; all analyses involve daily or longer means.

\section{Planetary wave analysis}

We apply a Fourier transform to 15 -day running means of $300 \mathrm{hPa}$ meridional wind averaged over $37.5-52.5^{\circ} \mathrm{N}$, obtaining amplitudes and phase positions of the circulation components of zonal wavenumbers $k=1-9$. Amplitudes are compared with a monthly climatology over 19812010 to calculate standardized anomalies.

\section{Return period analysis}

For each fitted temperature distribution analyzed in this study (skew normal and GEV for reanalysis data, and Gaussian KDEs for model data), we obtain the probability of exceedance of a given temperature anomaly (survival function; SF) as 1 minus its CDF. For model data, the four PDFs examined are the two ensemble means of single-member KDEs in each ensemble (Interactive versus Prescribed soil moisture) and the two ensemble-total PDFs grouping together all member-years in each ensemble. We then calculate return periods (as a function of temperature anomaly) as the inverse of SF, and estimate the return period of an event analogous to the observed heatwave, for each method. For the skew normal distribution fit to June-July daily mean temperatures (Fig. $5 \mathrm{~b}$ ), return period is calculated as $1 /(61 * \mathrm{SF})$, since SF represents a daily probability, in order to obtain the yearly return period of one day within the 61-day yearly period (06/01-07/31) exceeding a given temperature threshold. The historical periods we compare are two historical 21-year periods not sharing any years (1979-1999 and 2000-2020). For GEV (Fig. 5e) we consider one observation per year (the maximum daily mean temperature over June-July), and for model data (Fig. 4d) we also consider one observation per year (June mean), so the return period is simply $1 / \mathrm{SF}$.

GEV fits are calculated using the whole period's data, but are nonstationary such that the return levels evolve linearly each year. To calculate the fit, we linearly detrend the data over 1979-2020, fit all three parameters (location, scale, and shape) to the detrended data, and finally 
434 add the linear data trend back to the whole-period location parameter for each year, obtaining a

435 fit that shifts in temperature at a constant yearly rate with fixed shape and scale parameters.

436 However, a comparison of the obtained whole-period fits against empirical temperature

437 exceedance likelihoods in 1979-1999 vs. 2000-2020 implies that scale and/or shape parameters

438 may have changed, such that defining them as constants may produce conservative historical

439 probability ratios and current and future likelihood estimates (Supplementary Fig. 11). For

440 comparison with the skew normal method, we extract the fit shifted to the middle year of the

441 analyzed historical periods, i.e. 1989 and 2010, which is equivalent to calculating mean return

442 levels over each of the periods.

443 In order to conceptually standardize confidence intervals across differing methods, we

444 apply bootstrapping: for each method we fit the appropriate distribution to each of a large

445 number of realizations of the input data, obtained by resampling (drawing $n$ out of a given $n$

446 datapoints, with replacement allowed) many times. The confidence intervals represent certain

447 percentiles of return period at each temperature across all PDFs generated by the resampling 448 repetitions. We resample 1,000 times for each skew normal fit ( $n=1,281$ for the 21-year periods 449 of 61 days each year) and 10,000 times for the GEV fits ( $n=42$ or 43, excluding or including 450 2021), based on stabilizing percentile intervals with increasing repetitions. For model data, we 451 bootstrap the ensemble-total PDFs by resampling 5,000 times over $n=1,974$ member-months for 452 each ensemble, and do not show confidence intervals for ensemble means $(n=14)$.

454 Model experiment

455 The model experiment we utilize is referred to as CAM5-GOGA ${ }^{53,54}$. The atmospheric model is 456 CAM5 (National Center for Atmospheric Research [NCAR] Community Atmosphere Model, 457 version 5.3), which is the atmospheric component of the Community Earth System Model, 458 version $1.2^{55}$, at T42 spectral $\left(\sim 2.75^{\circ}\right)$ resolution. The GOGA (Global Ocean Global 459 Atmosphere) experiment involves forcing 16 members of CAM5 with historical monthly sea 460 surface temperatures (HadISSTv2 ${ }^{56}$ ) over the period 1856-2014. Greenhouse gases (GHGs) and 461 radiative forcing are fixed (GHGs at 2000 levels), and sea ice concentration follows HadISSTv2.

462 One 16-member ensemble allows soil moisture to interact with the atmospheric model, while the 463 other prescribes soil moisture as the monthly climatology over 1950-2015 at each location 464 derived from all members. We begin analysis in 1870 to avoid model spin-up effects and discard 
Non-peer reviewed preprint submitted to EarthArXiv (in review at Nature Climate Change)

465 two full members and all years after 2010 due to data discrepancies, resulting in a 14-member by 4662 -ensemble by 141-year dataset. For comparison with reanalysis, we standardize all anomalies, 467 based on the whole period for all grouped Prescribed members, for model data, and based on the 468 1981-2010 climatology for reanalysis data. 


\section{Acknowledgements}

471 We are thankful to Yutian Wu, Radley Horton, Deepti Singh, Colin Raymond, Cassandra

472 Rogers, and Richard Seager for valuable feedback on this work. We thank Donna Lee for

473 configuring, running, and making output available from CAM5-GOGA. Support for this work

474 was provided by NSF-AGS-1934358.

475

\section{$476 \quad$ Data Availability}

477 All ERA5 output used in this study is available from ECMWF at

478 https://cds.climate.copernicus.eu/cdsapp\#!/dataset/reanalysis-era5-single-levels. All

479 CAM5_GOGA output used in this study is available at https://doi.org/10.5281/zenodo.5800726.

481 Code Availability

482 All figures were produced using Python v.3.6

483 (https://www.python.org/downloads/release/python-360/). All code needed to reproduce the

484 main figures is available at https://github.com/sambartusek/pnw_hw_2021. 
Non-peer reviewed preprint submitted to EarthArXiv (in review at Nature Climate Change)

485

486

487

488

489

490

491

492

493

494

495

496

497

498

499

500

501

502

503

504

505

506

507

\section{$\underline{\text { References }}$}

1. Popovich, N. \& Choi-Schagrin, W. Hidden Toll of the Northwest Heat Wave: Hundreds of Extra Deaths. The New York Times (2021).

2. Excess Deaths Associated with COVID-19. https://www.cdc.gov/nchs/nvss/vsrr/covid19/excess_deaths.htm (2021).

3. Coroners. [No title]. https://www2.gov.bc.ca/gov/content/life-events/death/coronersservice/news-and-updates/heat-related.

4. Schramm, P. J. et al. Heat-Related Emergency Department Visits During the Northwestern Heat Wave - United States, June 2021. MMWR Morb. Mortal. Wkly. Rep. 70, 1020-1021 (2021).

5. US Census Bureau. American Housing Survey (AHS). https://www.census.gov/programssurveys/ahs.html.

6. Tigchelaar, M., Battisti, D. S. \& Spector, J. T. Work Adaptations Insufficient to Address Growing Heat Risk for U.S. Agricultural Workers. Environ. Res. Lett. 15, (2020).

7. US Drought Monitor Map Archive. https://droughtmonitor.unl.edu/Maps/MapArchive.aspx.

8. National Fire News. https://www.nifc.gov/fire-information/nfn.

9. Silverman, H., Guy, M. \& Sutton, J. Western wildfire smoke is contributing to New York City's worst air quality in 15 years. $C N N$ (2021).

10. Meehl, G. A. \& Tebaldi, C. More intense, more frequent, and longer lasting heat waves in the 21st century. Science 305, 994-997 (2004).

11. Perkins-Kirkpatrick, S. E. \& Lewis, S. C. Increasing trends in regional heatwaves. Nat. Commun. 11, 3357 (2020).

12. Philip, S. Y. et al. Rapid attribution analysis of the extraordinary heatwave on the Pacific 
Non-peer reviewed preprint submitted to EarthArXiv (in review at Nature Climate Change)

508 Coast. https://www.worldweatherattribution.org/wp-content/uploads/NW-US-extreme-heat509 2021-scientific-report-WWA.pdf.

510 13. Coumou, D. \& Robinson, A. Historic and future increase in the global land area affected by $511 \quad$ monthly heat extremes. Environ. Res. Lett. 8, 034018 (2013).

512 14. Power, S. B. \& Delage, F. P. D. Setting and smashing extreme temperature records over the $513 \quad$ coming century. Nat. Clim. Chang. 9, 529-534 (2019).

514 15. Fischer, E. M., Sippel, S. \& Knutti, R. Increasing probability of record-shattering climate $515 \quad$ extremes. Nat. Clim. Chang. 11, 689-695 (2021).

516 16. Petoukhov, V., Rahmstorf, S., Petri, S. \& Schellnhuber, H. J. Quasiresonant amplification 517 of planetary waves and recent Northern Hemisphere weather extremes. Proc. Natl. Acad. 518 Sci. U. S. A. 110, 5336-5341 (2013).

519 17. Petoukhov, V. et al. Role of quasiresonant planetary wave dynamics in recent boreal spring520 to-autumn extreme events. Proc. Natl. Acad. Sci. U. S. A. 113, 6862-6867 (2016).

521 18. Screen, J. A. \& Simmonds, I. Amplified mid-latitude planetary waves favour particular 522 regional weather extremes. Nat. Clim. Chang. 4, 704-709 (2014).

523 19. Kornhuber, K. et al. Summertime Planetary Wave Resonance in the Northern and Southern 524 Hemispheres. J. Clim. 30, 6133-6150 (2017).

525 20. Kornhuber, K. et al. Amplified Rossby waves enhance risk of concurrent heatwaves in 526 major breadbasket regions. Nat. Clim. Chang. 10, 48-53 (2019).

527 21. Mann, M. E. et al. Influence of Anthropogenic Climate Change on Planetary Wave 528 Resonance and Extreme Weather Events. Sci. Rep. 7, 45242 (2017).

529 22. Mann, M. E. et al. Projected changes in persistent extreme summer weather events: The role 530 of quasi-resonant amplification. Sci Adv 4, eaat3272 (2018). 
531 23. Kornhuber, K. \& Tamarin-Brodsky, T. Future changes in northern hemisphere summer 532 weather persistence linked to projected arctic warming. Geophys. Res. Lett. 48, (2021).

533 24. Hirschi, M. et al. Observational evidence for soil-moisture impact on hot extremes in $534 \quad$ southeastern Europe. Nat. Geosci. 4, 17-21 (2010).

535 25. Miralles, D. G., van den Berg, M. J., Teuling, A. J. \& de Jeu, R. A. M. Soil moisture536 temperature coupling: A multiscale observational analysis. Geophys. Res. Lett. 39, (2012).

537 26. Miralles, D. G., Teuling, A. J., van Heerwaarden, C. C. \& Vilà-Guerau de Arellano, J. 538 Mega-heatwave temperatures due to combined soil desiccation and atmospheric heat $539 \quad$ accumulation. Nat. Geosci. 7, 345-349 (2014).

540 27. Rasmijn, L. M. et al. Future equivalent of 2010 Russian heatwave intensified by weakening 541 soil moisture constraints. Nat. Clim. Chang. 8, 381-385 (2018).

542 28. Dirmeyer, P. A., Balsamo, G., Blyth, E. M., Morrison, R. \& Cooper, H. M. Land543 atmosphere interactions exacerbated the drought and heatwave over northern Europe during $544 \quad$ summer 2018. AGU Advances 2, (2021).

545 29. Seneviratne, S. I. et al. Investigating soil moisture-climate interactions in a changing 546 climate: A review. Earth-Sci. Rev. 99, 125-161 (2010).

547 30. Koster, R. D. et al. Regions of strong coupling between soil moisture and precipitation. $548 \quad$ Science 305, 1138-1140 (2004).

549 31. Cook, B. I., Smerdon, J. E., Seager, R. \& Coats, S. Global warming and 21st century $550 \quad$ drying. Clim. Dyn. 43, 2607-2627 (2014).

551 32. Cook, B. I., Ault, T. R. \& Smerdon, J. E. Unprecedented 21 st century drought risk in the $552 \quad$ American Southwest and Central Plains. Sci Adv 1, e1400082 (2015).

553 33. Dirmeyer, P. A. et al. Projections of the shifting envelope of Water cycle variability. Clim. 
Non-peer reviewed preprint submitted to EarthArXiv (in review at Nature Climate Change)

Change 136, 587-600 (2016).

34. Seneviratne, S. I., Lüthi, D., Litschi, M. \& Schär, C. Land-atmosphere coupling and climate change in Europe. Nature 443, 205-209 (2006).

35. Petoukhov, V. et al. Alberta wildfire 2016: Apt contribution from anomalous planetary wave dynamics. Sci. Rep. 8, 12375 (2018).

36. Archambault, H. M., Bosart, L. F., Keyser, D. \& Cordeira, J. M. A Climatological Analysis

37. Stuivenvolt Allen, J., Simon Wang, S.-Y., LaPlante, M. D. \& Yoon, J.-H. Three western pacific typhoons strengthened fire weather in the recent northwest U.s. conflagration. Geophys. Res. Lett. 48, (2021).

38. Oey, L.-Y. \& Chou, S. Evidence of rising and poleward shift of storm surge in western North Pacific in recent decades. J. Geophys. Res. C: Oceans 121, 5181-5192 (2016).

39. Sharmila, S. \& Walsh, K. J. E. Recent poleward shift of tropical cyclone formation linked to Hadley cell expansion. Nat. Clim. Chang. 8, 730-736 (2018).

40. Wang, R. \& Wu, L. Influence of Track Changes on the Poleward Shift of LMI Location of Western North Pacific Tropical Cyclones. J. Clim. 32, 8437-8445 (2019).

571 41. Schumacher, D. L. et al. Amplification of mega-heatwaves through heat torrents fuelled by upwind drought. Nat. Geosci. 12, 712-717 (2019).

573 42. Wang, J. et al. Changing lengths of the Four Seasons by global warming. Geophys. Res. Lett. 48, (2021). Distribution. J. Clim. 27, 7976-7993 (2014). 
577 44. Swain, D. L., Singh, D., Touma, D. \& Diffenbaugh, N. S. Attributing Extreme Events to 578 Climate Change: A New Frontier in a Warming World. One Earth 2, 522-527 (2020).

579 45. van Oldenborgh, G. J. et al. Pathways and pitfalls in extreme event attribution. Clim.

$580 \quad$ Change 166, 13 (2021).

581 46. McKinnon, K. A., Rhines, A., Tingley, M. P. \& Huybers, P. The changing shape of 582 Northern Hemisphere summer temperature distributions. J. Geophys. Res. 121, 8849-8868 $583 \quad$ (2016).

584 47. Volodin, E. M. \& Yurova, A. Y. Summer temperature standard deviation, skewness and 585 strong positive temperature anomalies in the present day climate and under global warming conditions. Clim. Dyn. 40, 1387-1398 (2013).

587 48. Lin, N. \& Emanuel, K. Grey swan tropical cyclones. Nat. Clim. Chang. 6, 106-111 (2015).

588 49. Dirmeyer, P. A. The terrestrial segment of soil moisture-climate coupling. Geophys. Res. $589 \quad$ Lett. 38, (2011).

590 50. Schwingshackl, C., Hirschi, M. \& Seneviratne, S. I. Quantifying Spatiotemporal Variations 591 of Soil Moisture Control on Surface Energy Balance and Near-Surface Air Temperature. $J$. $592 \quad$ Clim. 30, 7105-7124 (2017).

593 51. Mueller, B. \& Seneviratne, S. I. Hot days induced by precipitation deficits at the global $594 \quad$ scale. Proc. Natl. Acad. Sci. U. S. A. 109, 12398-12403 (2012).

595 52. Hersbach, H. et al. The ERA5 global reanalysis. Quart. J. Roy. Meteor. Soc. 146, 1999$5962049(2020)$.

597 53. Lee, D. E., Ting, M., Vigaud, N., Kushnir, Y. \& Barnston, A. G. Atlantic Multidecadal 598 Variability as a Modulator of Precipitation Variability in the Southwest United States. $J$.

$599 \quad$ Clim. 31, 5525-5542 (2018). 
Non-peer reviewed preprint submitted to EarthArXiv (in review at Nature Climate Change)

600 54. Pomposi, C., Giannini, A., Kushnir, Y. \& Lee, D. E. Understanding Pacific Ocean influence 601 on interannual precipitation variability in the Sahel. Geophys. Res. Lett. 43, 9234-9242 $602 \quad$ (2016)

603 55. Neale, R. B. et al. The Mean Climate of the Community Atmosphere Model (CAM4) in 604 Forced SST and Fully Coupled Experiments. J. Clim. 26, 5150-5168 (2013).

605 56. Titchner, H. A. \& Rayner, N. A. The Met Office Hadley Centre sea ice and sea surface 606 temperature data set, version 2: 1. Sea ice concentrations. J. Geophys. Res. 119, 2864-2889 $607 \quad$ (2014). 


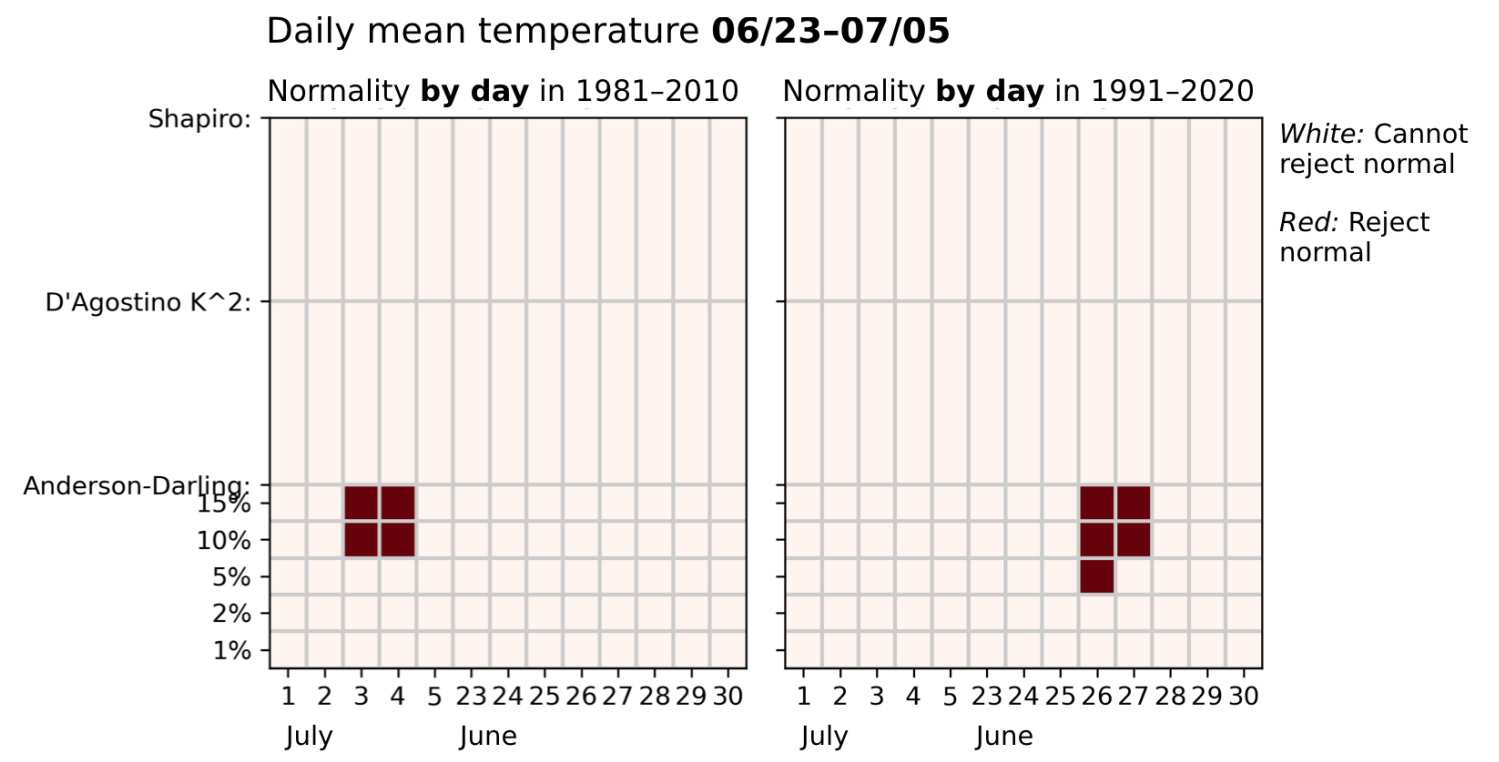

Daily mean temperature $06 / 01-07 / 31$

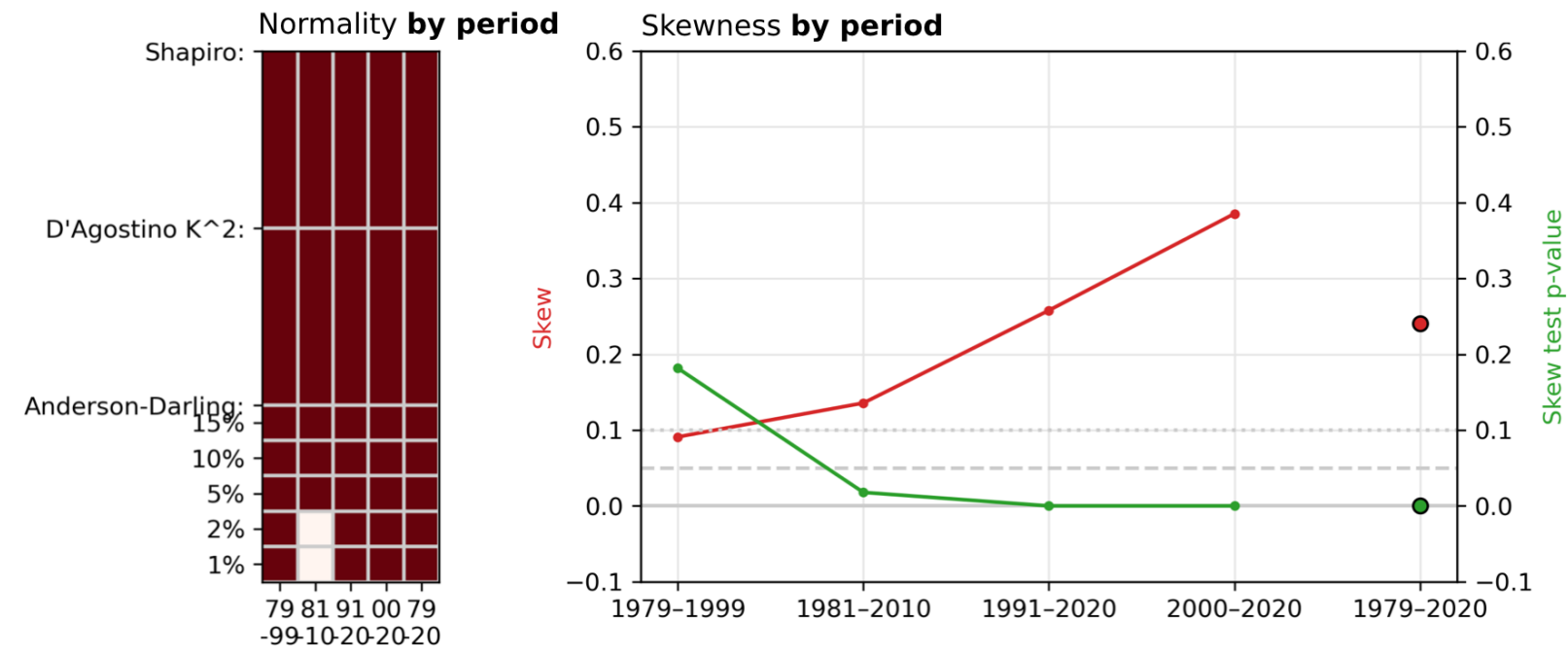

2

3 Supplementary Fig. 1: Normality and skew tests for temperature distributions over

4 historical periods. Top row: for daily mean temperature over 06/23-07/05, the plots show

5 results from three normality tests determining whether the dataset (individual days over the

6 1981-2010 period (left) and 1991-2020 period (right)) can be statistically distinguished from

7 normal (red) or not (white). Shapiro and D'Agostino tests report a single output, and the

8 Anderson-Darling test reports at 5 different confidence levels. These results only register 
9 interannual variability (one day per year). Bottom row: The left plot compares the daily

10 temperatures over all of June and July subset for 5 different periods (1979-1999, 1981-2010,

11 1991-2020, 2000-2020, and 1979-2020, from left to right). The right plot shows the skewness

12 (red) calculated for temperature data for each of the 5 period subsets, along with the $p$-value of

13 the skew test (.1 and .05 significance levels indicated). These results register both interannual

14 and intra-annual variability (61 days per year over 21-, 30-, or 42-year periods). 

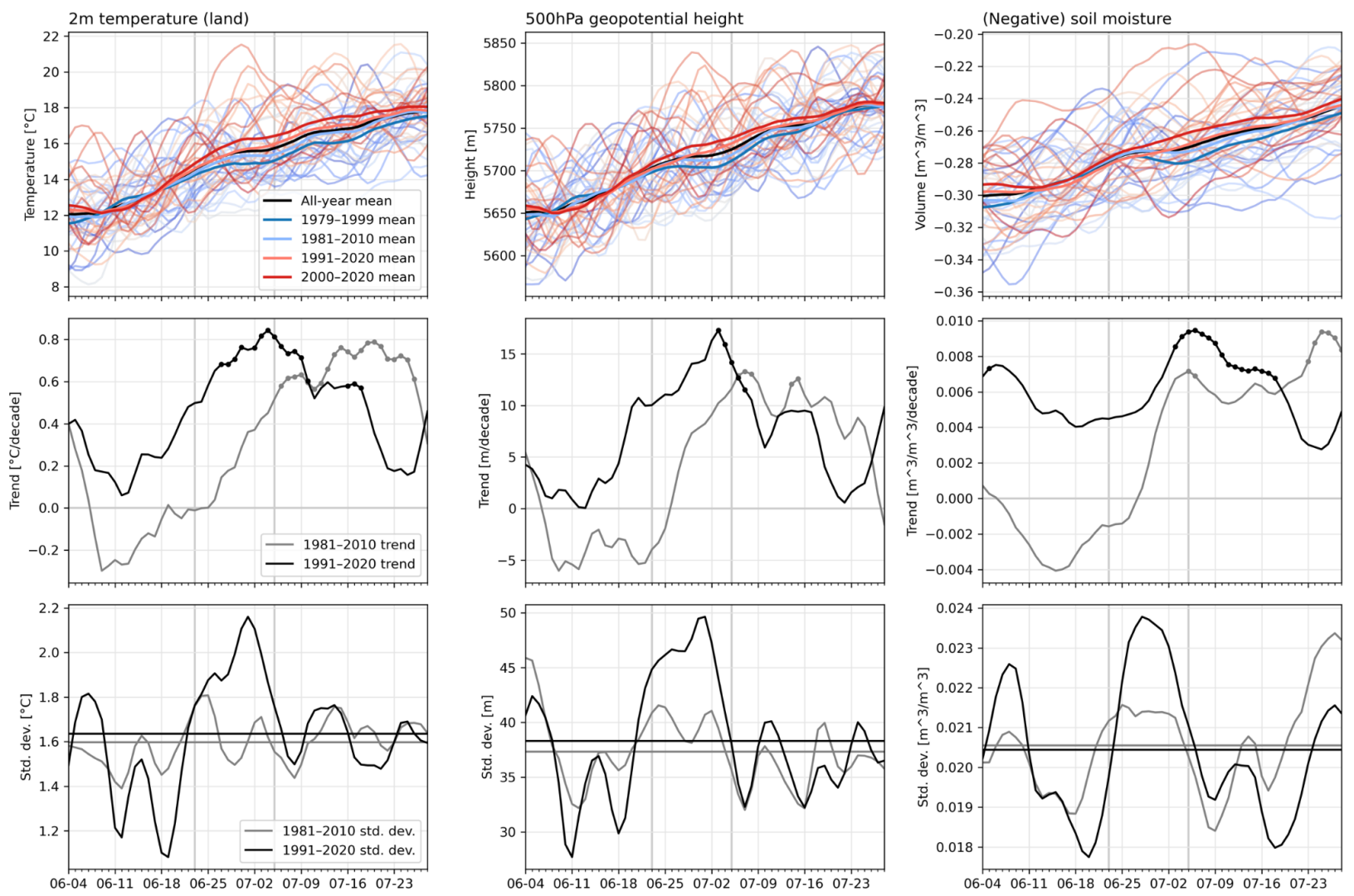

\section{Supplementary Fig. 2: Historical changes in temperature, geopotential height, and soil} moisture and their interannual variability. PNW-mean temperature, geopotential height, and soil moisture data from ERA5 over the entire period of analysis except 2021 (1979-2020, throughout June and July). All data are 7-day running means of raw (non-anomalous) data. Gray vertical lines mark 06/23 and 07/05. Top row: color-coded data for each year (blue in 1979 to red in 2020), with means throughout the various analysis periods overlaid according to the legend. Second row: linear trends in data over 1981-2010 and 1991-2020, marked with dots where significant at 90\% level. Bottom row: interannual standard deviations across 1981-2010 and 1991-2020, with horizontal lines demarcating the June-July mean for each period. The bottom row shows that in the PNW, standard deviation is increasing for temperature and geopotential height over June and July as a whole, and especially for late-June-early-July (when soil moisture standard deviation is also increasing sharply) — which is likely associated with 
30 warming trends shifting earlier in the year in accordance with an advancing summer onset (as 31 illustrated in the left panel of the middle row).

32 

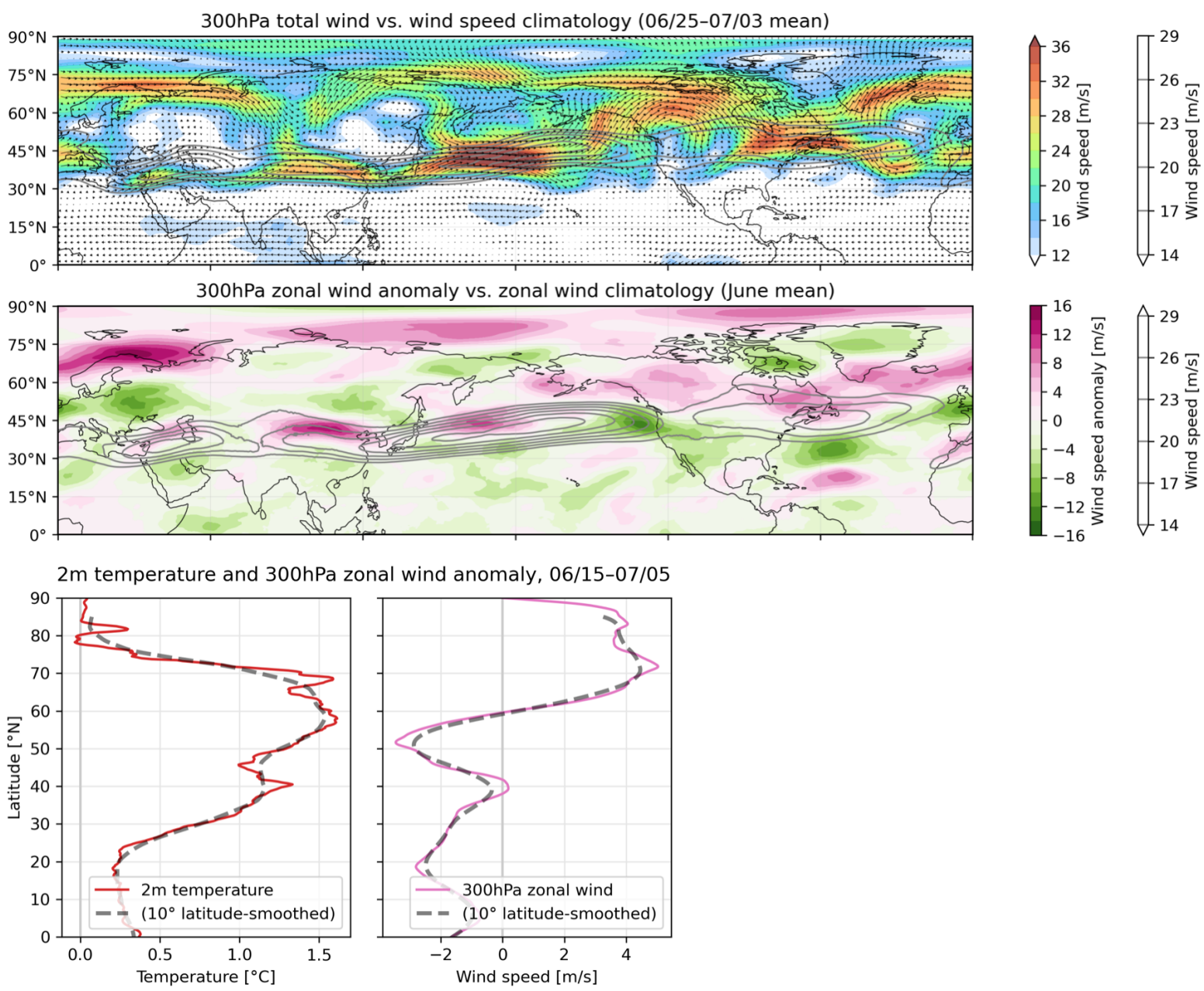

34 Supplementary Fig. 3: Total wind, zonal wind, and temperature anomalies in summer

35 2021. Top: anomalous total wind over $06 / 25-07 / 03$, with direction in vectors and magnitude in

36 vectors and color, compared with climatological total wind speed in gray contours. Middle:

37 June-mean anomalous zonal wind in color compared with climatological zonal wind in gray

38 contours. Bottom: 06/15-07/15-mean 2m temperature and zonal wind anomalies and their 10-

39 degree smoothings. 


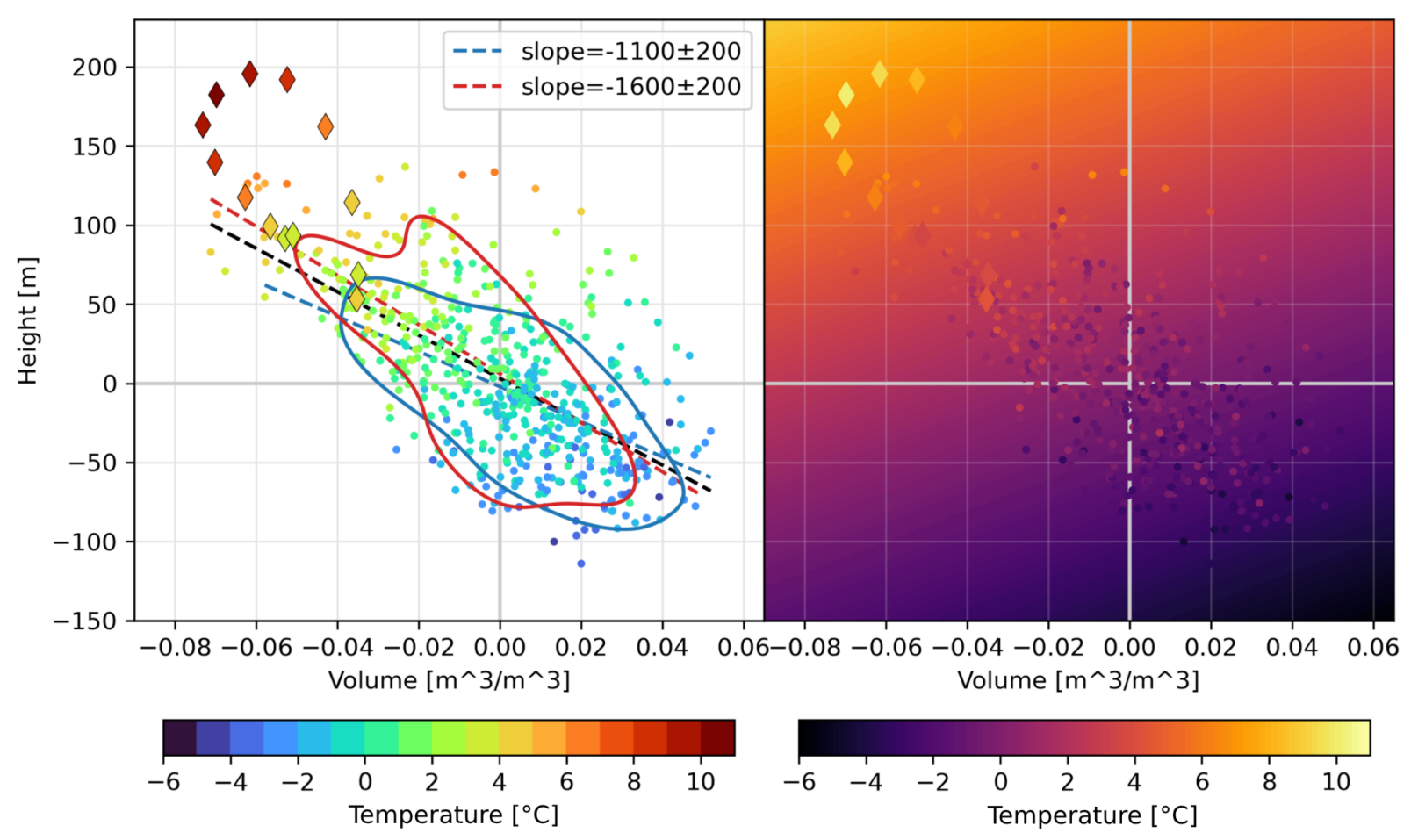

42 Supplementary Fig. 4: Comparison of observed temperature versus multiple linear

43 regression prediction. Left panel: Fig. 3c, copied for ease of interpretation. Right panel: in the

44 background gradient, the temperature modeled by a multiple linear regression based on both soil

45 moisture and geopotential height anomalies, with the regressions calculated from the 3-day mean

46 data over 06/23-07/05 from 1979-2020. The point data show observed temperatures (i.e., the

47 same values as shown in the left panel, but according to a different colormap), with dots for

48 1979-2020 and diamonds for 2021. The difference between the observed temperature (scattered

49 point data) and the predicted temperature (the background gradient value underlying each

50 scattered point) is what is shown in Fig. $3 \mathrm{~d}$. 


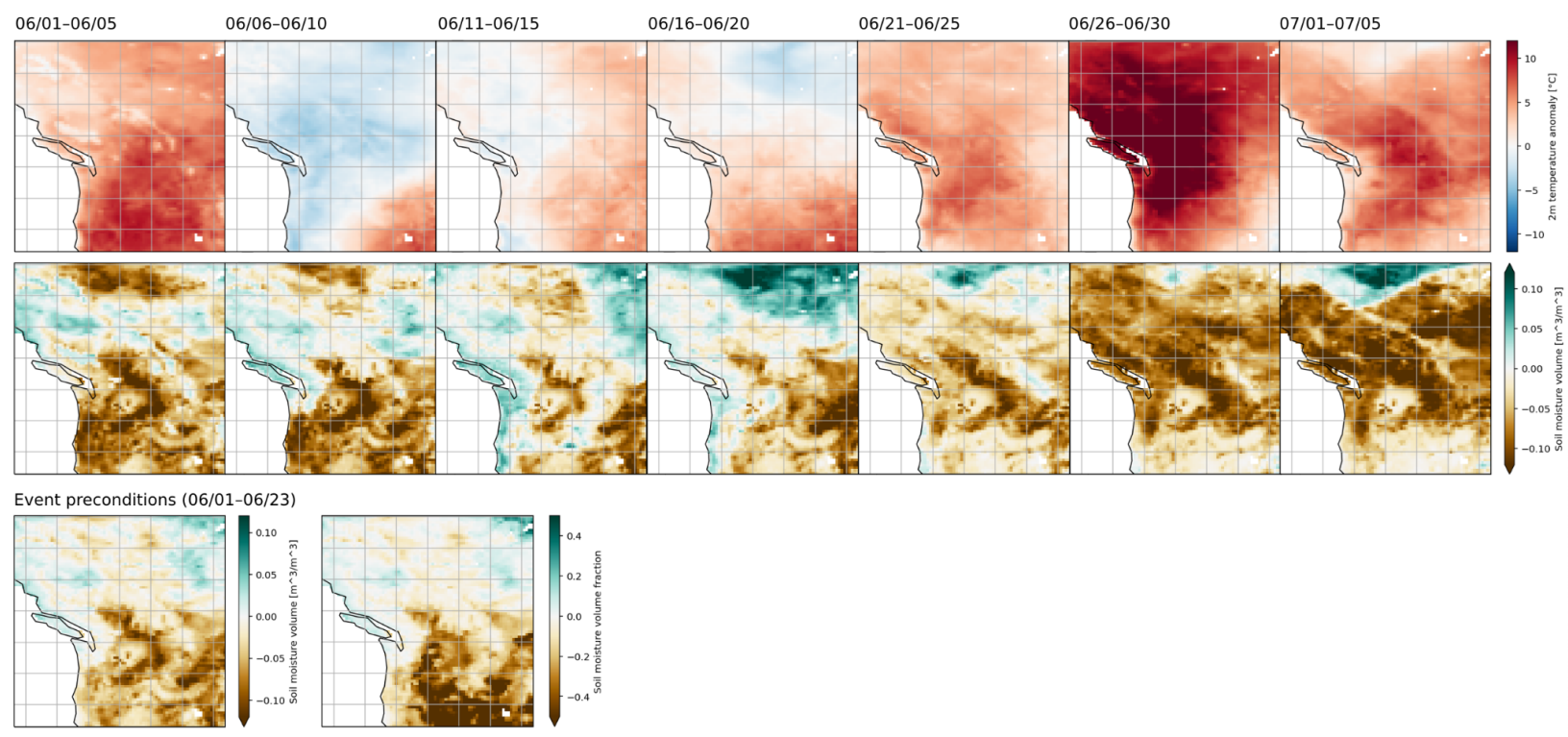

52 Supplementary Fig. 5: Early summer evolution of temperature and soil moisture

53 anomalies, and soil preconditions for the late-June heatwave. Top row: 5-day means of $2 \mathrm{~m}$

54 (land) temperature anomalies over the PNW from 06/01 to 07/05. Second row: as in top row but

55 for soil moisture anomalies. Bottom row: 06/01-06/23 mean soil moisture anomalies over the

56 PNW (left) and the same data expressed as fraction of climatology (right), emphasizing large

57 fractional anomalies where soil moisture is climatologically low and thus non-fractional

58 anomalies are limited in magnitude, compared to wetter areas. (I.e., soil moisture anomalies in

59 Fig. 1c show comparatively small dry anomalies in the southwest US despite deep drought,

60 versus the PNW.) 


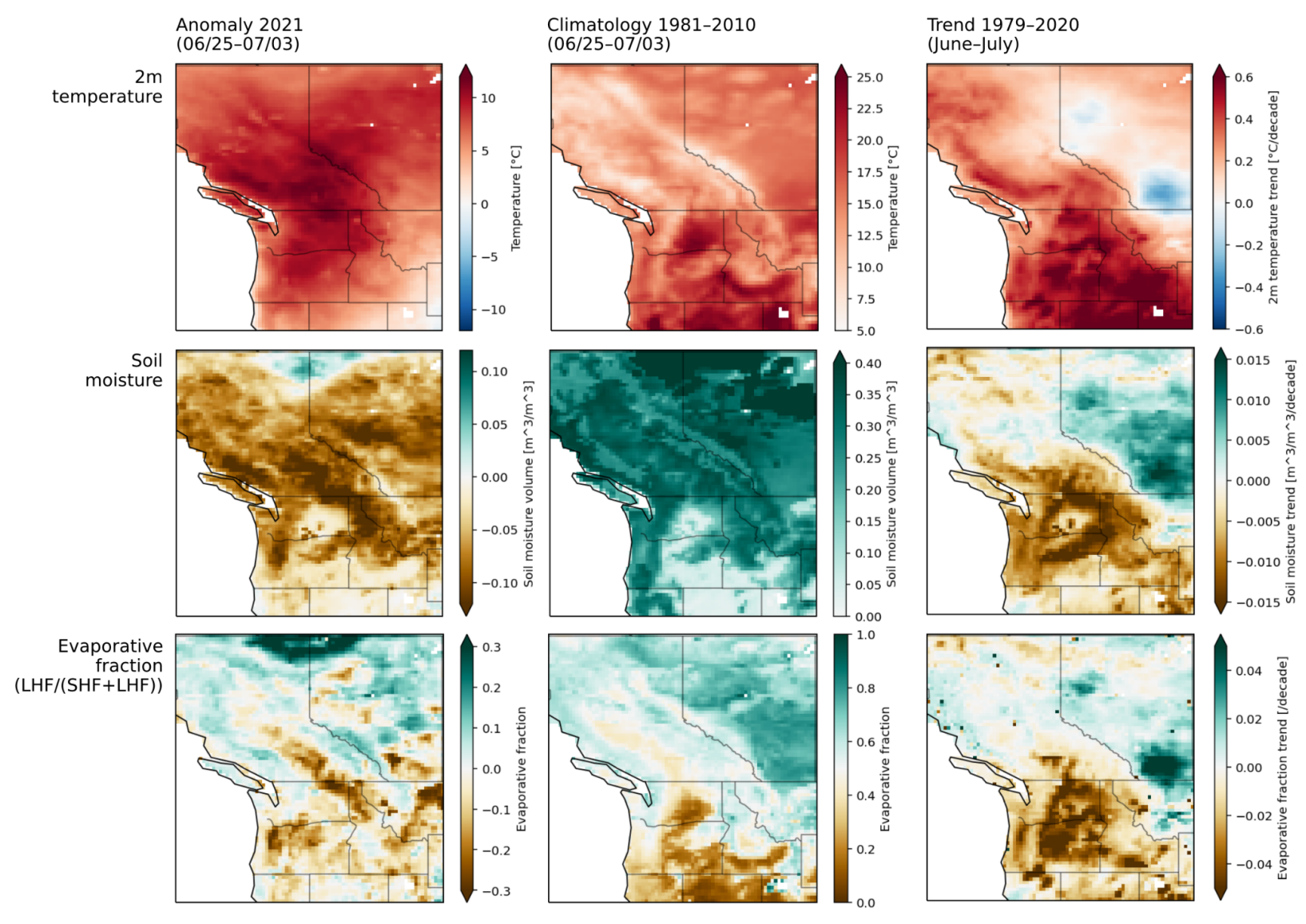

62 Supplementary Fig. 6: PNW land-atmosphere system anomalies during the 2021 heatwave,

63 contextualized by their climatologies and trends. Heatwave anomaly (06/25-07/03) (left

64 column), climatology during the same period (middle column), and multidecadal June-July

65 trend (right column), for $2 \mathrm{~m}$ temperature (top row), soil moisture (middle row) and

66 evaporative fraction (bottom row). Many low- to mid-elevation, interior, semi-arid and

67 Mediterranean climate areas (across eastern Oregon and Washington, Idaho, and British

68 Columbia) experienced the highest temperature, soil moisture, and evaporative fraction

69 anomalies, and many such areas are experiencing strong multidecadal trends in the same

70 direction. 


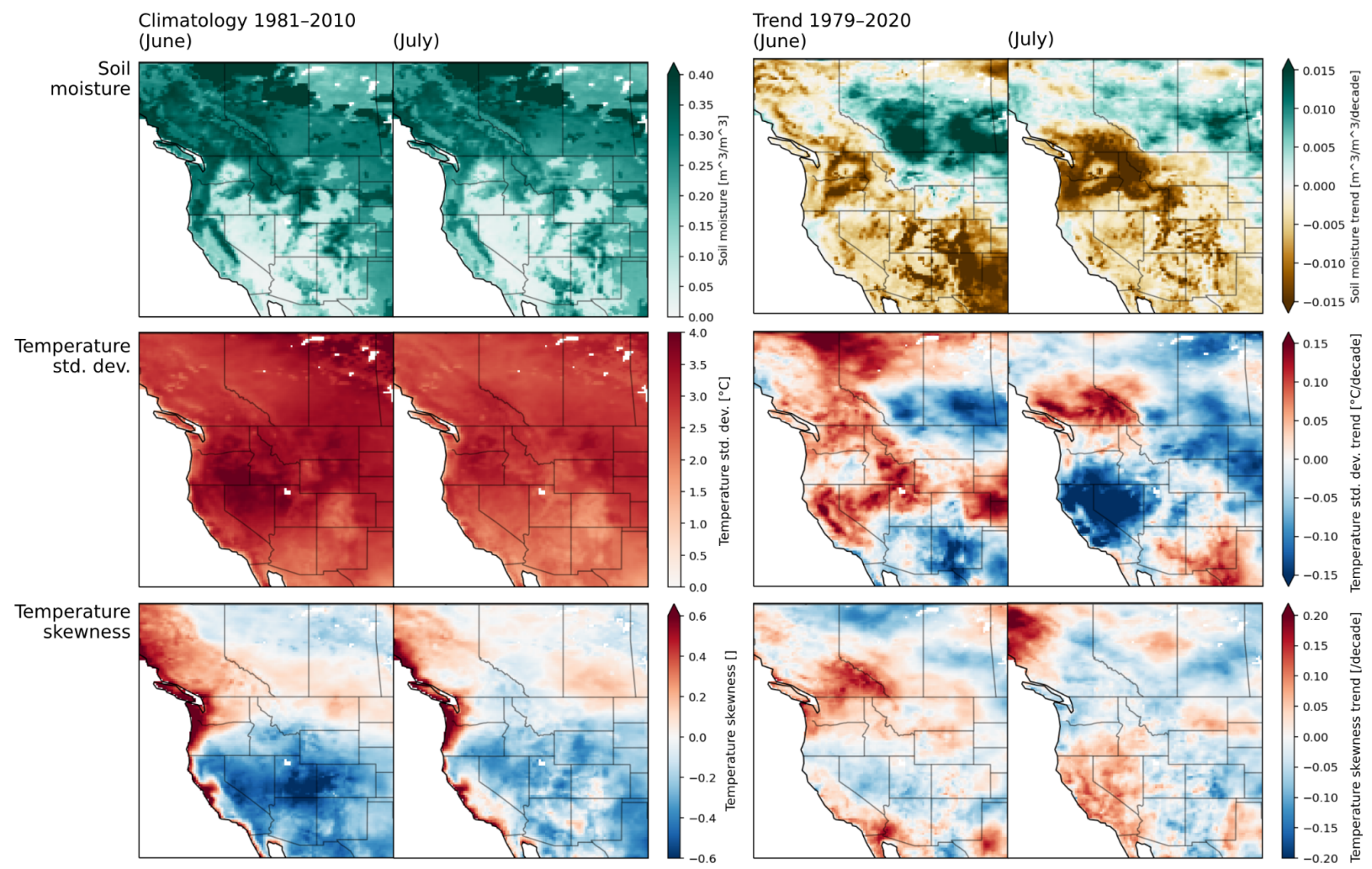

72 Supplementary Fig. 7: Soil moisture trends and temperature intra-annual variability

73 trends across western North America. Climatology and multi-decadal trend for (top row) soil

74 moisture, (middle row) intra-annual standard deviation (i.e., calculated within June or July of

75 each year) of temperature, and (bottom row) intra-annual skewness of temperature, for daily

76 mean data throughout June (left sub-panels) and July (right sub-panels). 

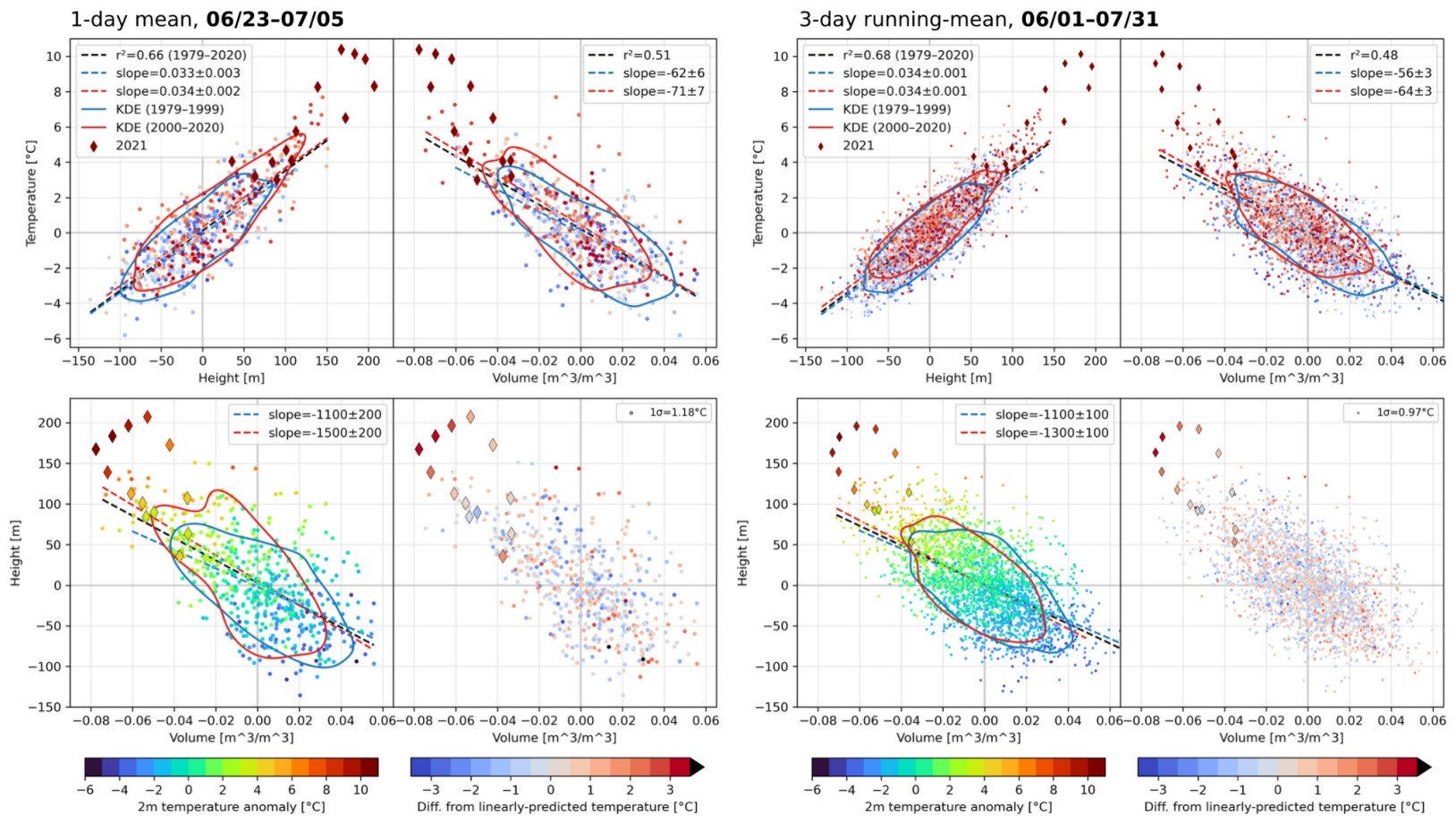

78 Supplementary Fig. 8: As in Fig. 3a-d but for daily mean data over 06/23-07/05 (left) and 3-

79 day running mean data over 06/01-07/31 (right). 

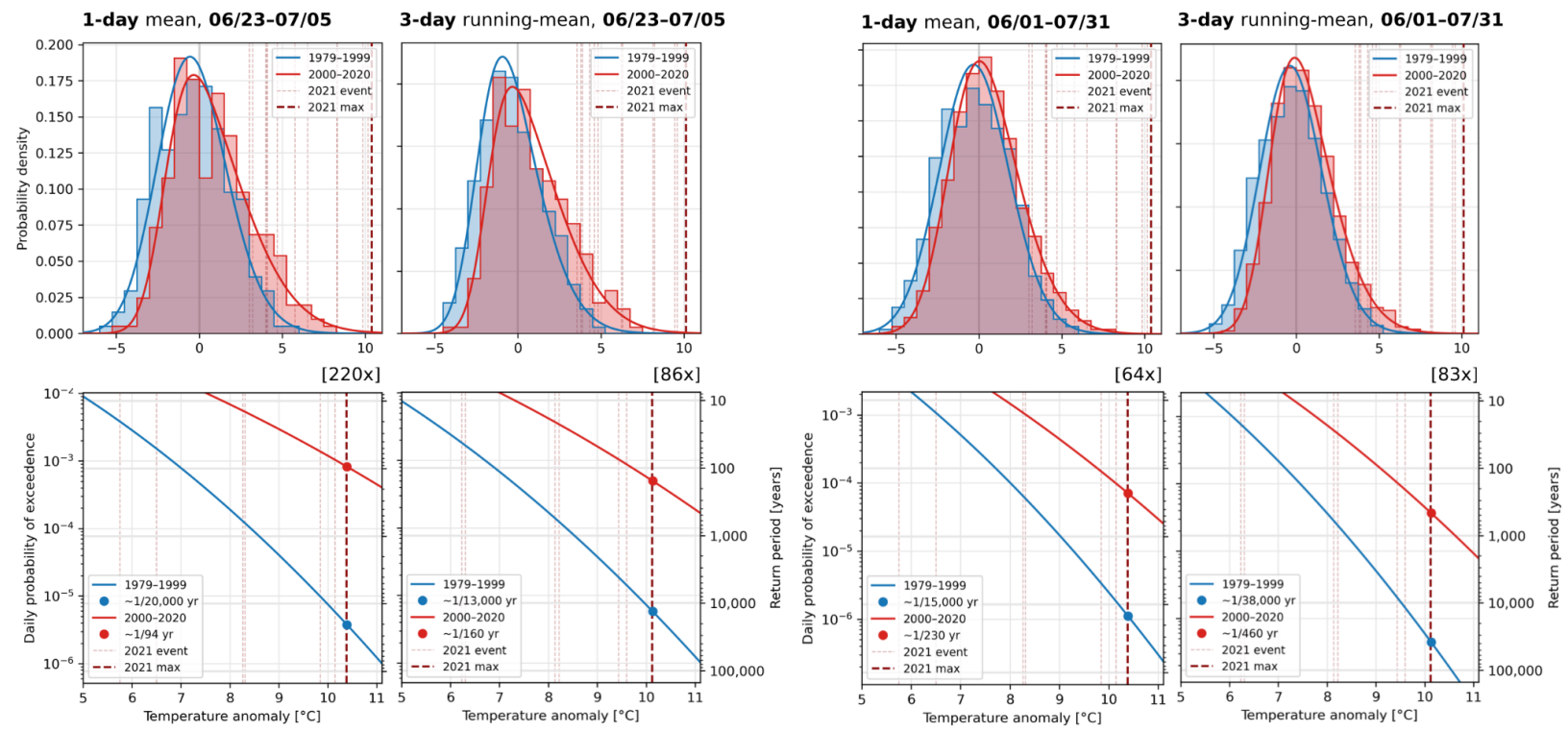

82 Supplementary Fig. 9: As in Fig. 5a-b but for daily mean temperatures over 06/23-07/05 (left),

83 3-day running mean temperatures over 06/23-07/05 (second from left), daily mean temperatures

84 over 06/01-07/31 (second from right), and 3-day running mean temperatures over 06/01-07/31

85 (right). The second-from-right column is the result shown in Fig. 5a-b. 


\section{June-mean PNW-mean:}
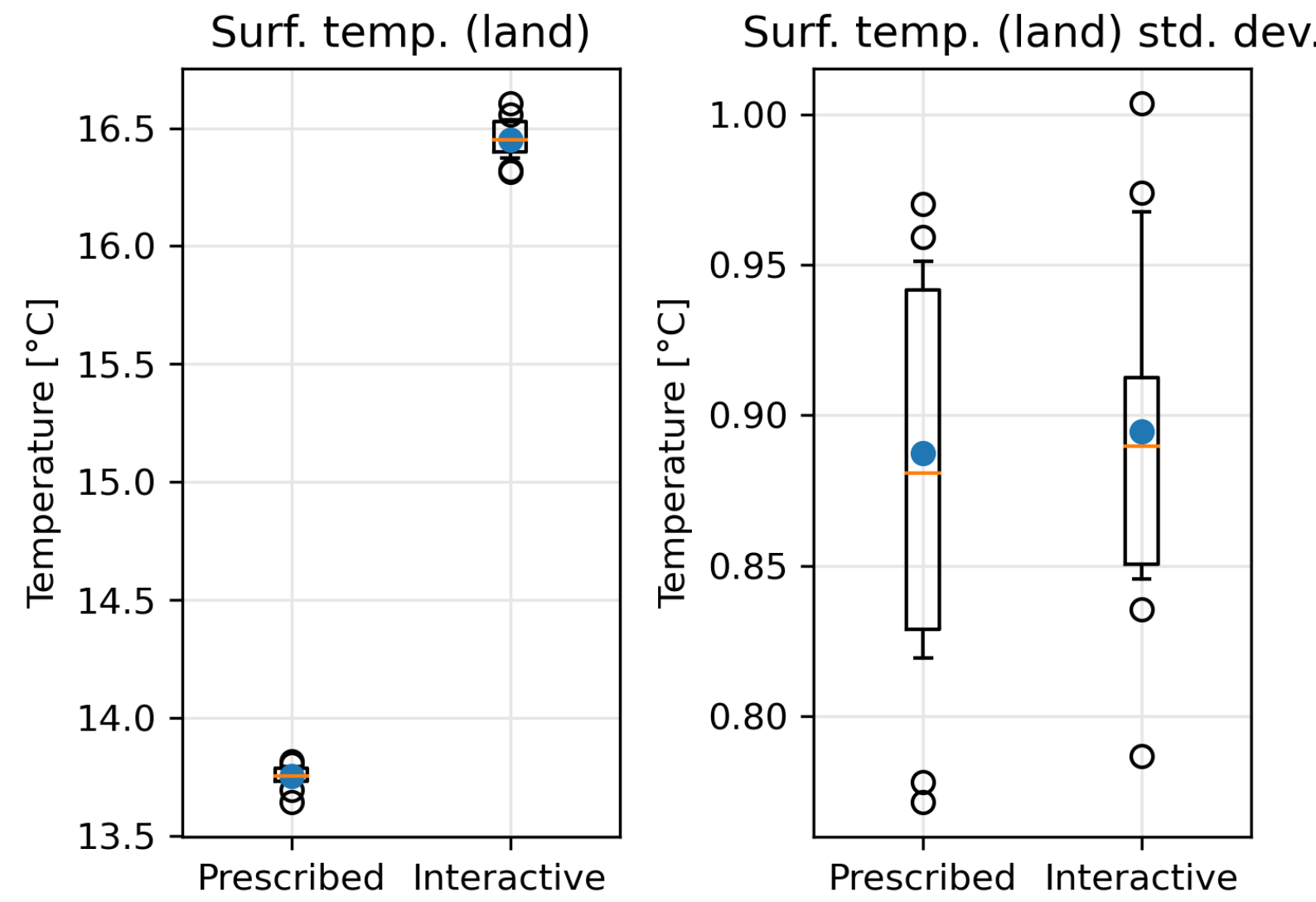

87 Supplementary Fig. 10: Shift and variability changes of June-mean PNW-mean

88 temperature in the model experiment. Boxplots show the model member spread, with the two

89 most distant members towards either end of the 14-member distribution shown as individual

90 dots. Blue dots show the ensemble total (all member-months) and orange lines show the

91 ensemble mean. The left plot is the mean surface temperature, and the right plot is the surface

92 temperature standard deviation. All standard deviations are calculated internally for each

93 member, i.e., across each member's entire 1870-2010 run. 
June-July daily mean temperatures
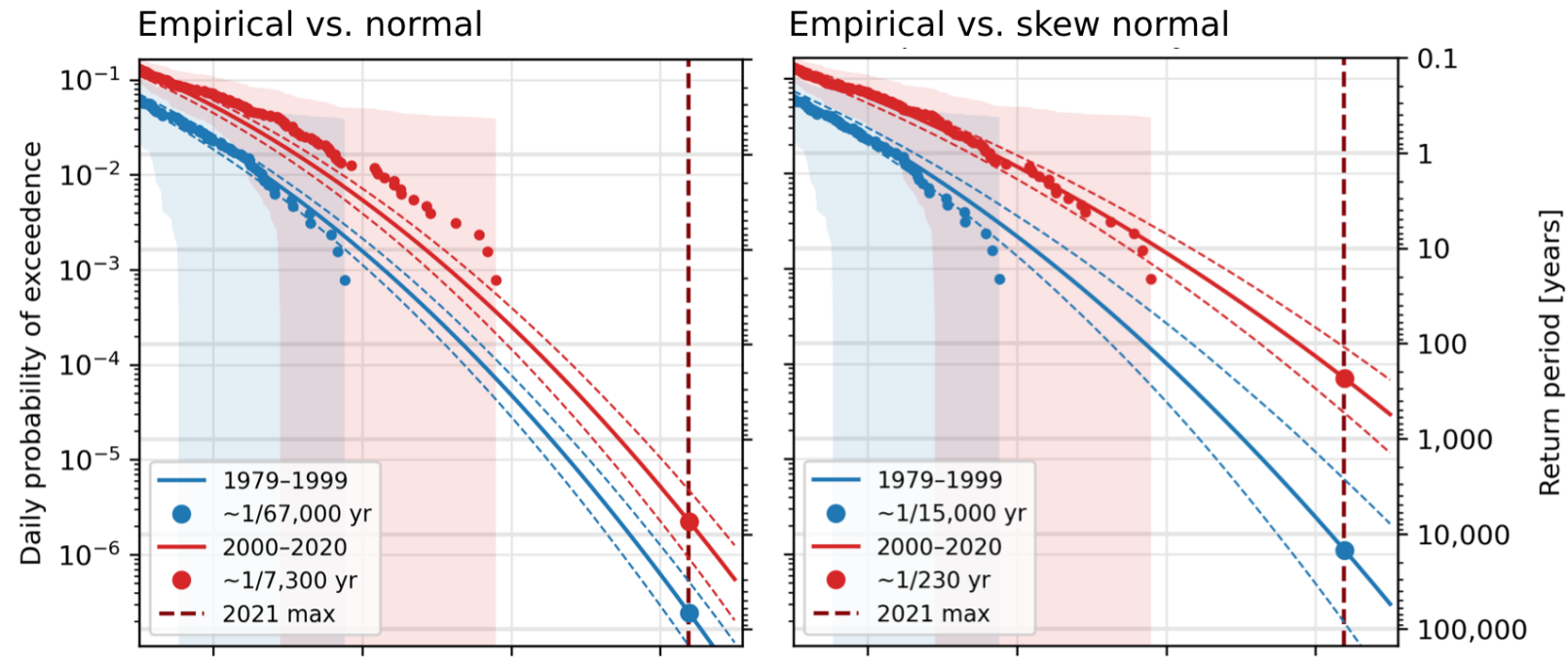

June-July-max daily mean temperature
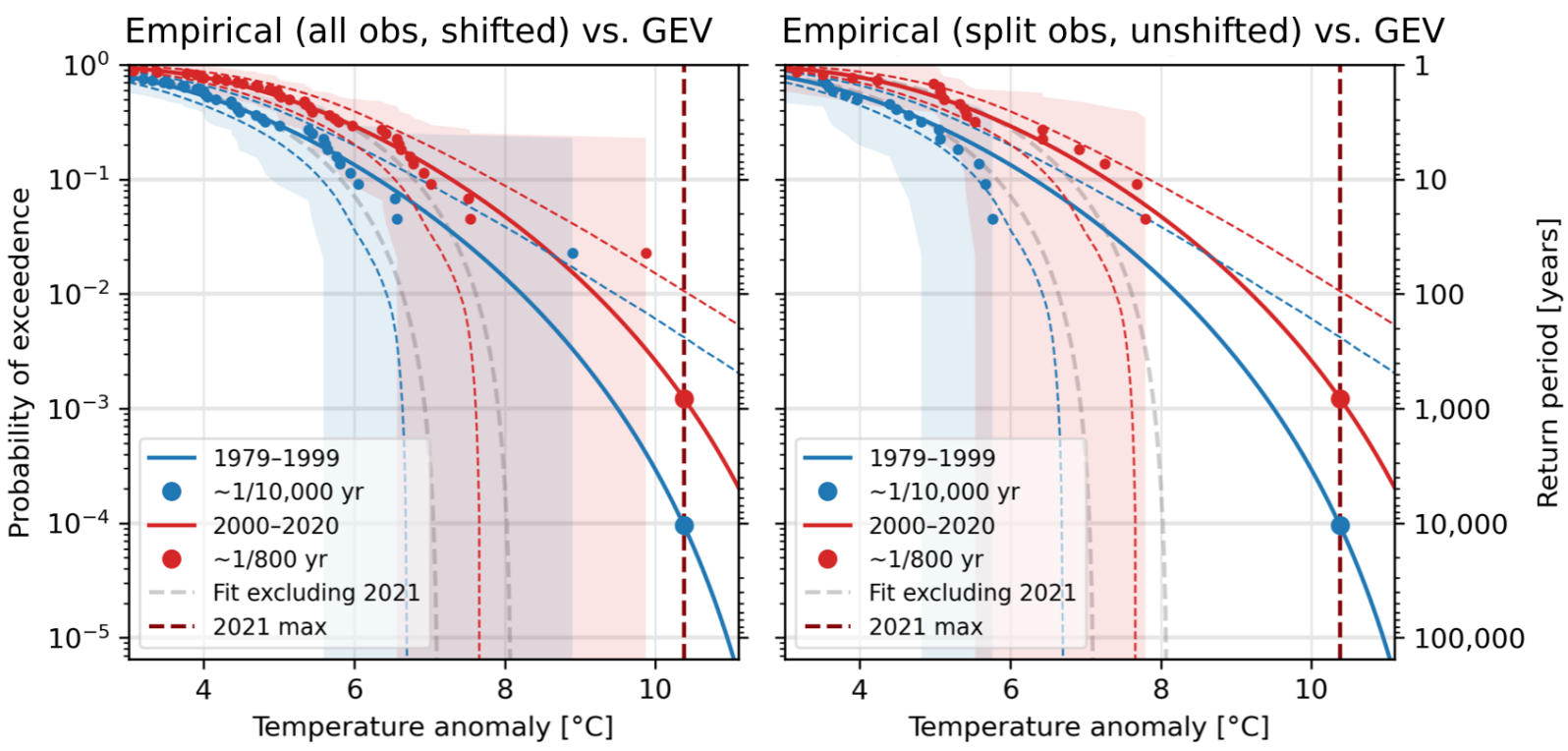

95 Supplementary Fig. 11: Fitted temperature distributions compared to empirical

96 probabilities and return periods. Top row: Normal and skew normal distributions are fit to all

97 June-July daily temperatures in the two historical periods. Small dots and shaded regions (same

98 between left and right plots) show empirical exceedance probabilities and return periods for

99 observed temperatures in each period and the $90 \%$ confidence interval for the empirical CDF.

100 Exceedance probabilities are estimated as $1-i /(n+1)$, with $n$ the number of observations in each

101 period and $i$ their ranking in ascending temperature order. Smooth curves show the fitted

102 distributions' exceedance probabilities and return periods as a function of temperature, with

103 dashed $90 \%$ bootstrapped confidence intervals. A normal distribution severely underestimates 
104 the empirically strong right tail for the 2000-2020 period, consistent with Supplementary Fig. 1

105 (which also demonstrates positive skewness for 1979-1999), while a skew normal distribution

106 brings the fit substantially closer to observations. Nonetheless, the most extreme observation lies

107 below the fit's 90\% confidence interval, indicating the caution needed when extrapolating out of

108 the sample - however, this effect is larger for 1979-1999, implying that the historical probability

109 ratios derived from this method may be conservative. Empirical confidence intervals are large

110 and encompass both fitted distributions. Bottom row: Here, the fits are constant between left and

111 right plots but the observations are presented differently. Fits are as in Fig. 5, calculated from

112 June-July-maximum daily temperatures over 1979-2021 (red and blue solid and dashed curves)

113 or excluding 2021 (gray dashed curves), with location parameter linearly shifted to 1989 (blue)

114 and 2010 (red), the central years of the 21-year comparison periods. Observations up to 2020

115 roughly follow the fits - in fact, they follow the including-2021 fit comparably well to (or better

116 than) the excluding-2021 fit. The 2021 observation (the most extreme dot in each color; shifted

117 left by the amount of linear warming between each central year and 2021) remains outside of the

118 fits' $90 \%$ confidence intervals. In the right plot, observations are split into 1979-1999 and 2000-

119 2020. The difference in their empirical return period curve shapes suggests a changing shape

120 and/or scale parameter over time, indicating that results assuming shifting location but fixed

121 shape and scale parameters (Fig. 5d-f) may underestimate current and future event probabilities,

122 and overestimate past event probabilities, thereby also conservatively reporting historical

123 probability ratios. 